\title{
HLW Glass Studies: Development of Crystal-Tolerant HLW Glasses
}

J Matyáš

AR Huckleberry

CP Rodriguez
JB Lang

AT Owen

AA Kruger

April 2012

Pacific Northwest

NATIONAL LABORATORY

Proudly Operated by Battelle Since 1965 


\title{
DISCLAIMER
}

This report was prepared as an account of work sponsored by an agency of the United States Government. Neither the United States Government nor any agency thereof, nor Battelle Memorial Institute, nor any of their employees, makes any warranty, express or implied, or assumes any legal liability or responsibility for the accuracy, completeness, or usefulness of any information, apparatus, product, or process disclosed, or represents that its use would not infringe privately owned rights. Reference herein to any specific commercial product, process, or service by trade name, trademark, manufacturer, or otherwise does not necessarily constitute or imply its endorsement, recommendation, or favoring by the United States Government or any agency thereof, or Battelle Memorial Institute. The views and opinions of authors expressed herein do not necessarily state or reflect those of the United States Government or any agency thereof.

\author{
PACIFIC NORTHWEST NATIONAL LABORATORY \\ operated by \\ BATTELLE \\ for the \\ UNITED STATES DEPARTMENT OF ENERGY \\ under Contract DE-AC05-76RL01830
}

Printed in the United States of America

Available to DOE and DOE contractors from the

Office of Scientific and Technical Information,

P.O. Box 62, Oak Ridge, TN 37831-0062;

ph: (865) 576-8401

fax: $(865) 576-5728$

email: reports@adonis.osti.gov

\author{
Available to the public from the National Technical Information Service \\ 5301 Shawnee Rd., Alexandria, VA 22312 \\ ph: (800) 553-NTIS (6847) \\ email: orders $a n$ tis.gov $<$ http://www.ntis.gov/about/form.aspx> \\ Online ordering: http://www.ntis.gov
}

This document was printed on recycled paper. 


\title{
HLW Glass Studies: Development of Crystal-Tolerant HLW Glasses
}

\author{
J Matyáš JB Lang \\ AR Huckleberry AT Owen \\ CP Rodriguez \\ AA Kruger
}

April 2012

Prepared for

the U.S. Department of Energy

under Contract DE-AC05-76RL01830

Pacific Northwest National Laboratory

Richland, Washington 99352

\footnotetext{
${ }^{1}$ U.S. Department of Energy, Office of River Protection, Richland, Washington.
} 



\section{Summary}

Ten glasses were prepared from high-level waste (HLW) AZ-101 simulant and additives. Eight of them were evaluated with a double crucible test for the effect of $\mathrm{Cr}, \mathrm{Ni}, \mathrm{Fe}, \mathrm{Al}, \mathrm{Li}$, and $\mathrm{RuO}_{2}$ on the accumulation rate of spinel crystals in the glass discharge riser of the HLW melter. The thicknesses of accumulated layers were incorporated into previously developed model of spinel settling (Matyáš et al. 2010a). In addition, the liquidus temperature $\left(T_{L}\right)$ of glasses was measured and their crystallinity in mass \% of spinel determined for heat-treatments at various temperatures for $24 \mathrm{~h}$. The remaining two glass compositions enriched with $\mathrm{Rh}_{2} \mathrm{O}_{3}$ and $\mathrm{RuO}_{2}$ were investigated with scanning electron microscopy (SEM) and x-ray tomography for agglomeration of particles and impact of agglomerates on accumulation rate.

The experimental study of spinel accumulation indicated that high concentrations of spinel-forming constituents in the glass can produce settling layers of a few $\mathrm{cm}$ thick in a few weeks. An excessive agglomeration of spinel in high-Ni-Fe glass (Ni1.5/Fe17.5) with agglomerates bigger than $500 \mu \mathrm{m}$ resulted in the accumulation rate $\sim 53.8 \mu \mathrm{m} / \mathrm{h}$, which will produce $\sim 2.6 \mathrm{~cm}$ thick layer in just 20 days of melter idling and can potentially plug the riser. Can noble metals decrease significantly this accumulation rate? There is an indication that they can. Additions of $\mathrm{RuO}_{2}$ (in the form of ruthenium nitrosyl nitrate) to high-Ni glass (Ni1.5) effectively slowed down or stopped the spinel accumulation because of their effect on decreasing the average crystal size below $10 \mu \mathrm{m}$. Can the accumulation of thick but noncompacted spinel layer prevent the plugging of the riser? Maybe it can. Then, the additions of $\mathrm{Al}_{2} \mathrm{O}_{3}$ and $\mathrm{Li}_{2} \mathrm{O}$ to glasses containing high concentration of spinel constituents might be the way. These components slowed down the growth of individual crystals but promoted the formation of a dendritic network of large needle-like spinel structures, which resulted in the non-compacted layers. There is a reasonable chance that spinel crystals locked in this configuration can be removed with glass during the pouring into canister.

The previously developed model (Matyáš et al. 2010a) predicts well, $\mathrm{R}^{2}=0.981$, the accumulation of crystals in the glasses with no or small-scale agglomeration, in which spinel settles as individual crystals and/or as clusters of a few crystals. But, in the case of excessive agglomeration, observed in the Ni1.5/Fe17.5 glass, the model under predicts the thicknesses of deposited layers. This under prediction was getting gradually worse with time as an increased number of larger agglomerates formed. Another factor that was not depicted by the model and that affected greatly the accumulation of spinel was the formation of 3D network of spinel needle-like structures in the Ni1.5/Al10 and Ni1.5/Li.38 glasses, which prevented a formation of a dense settled layer.

The $T_{L}$ 's of tested glasses as determined with optical microscopy was between 950 to $1105^{\circ} \mathrm{C}$. We have also measured the mass concentrations of spinel at different temperatures. They ranged from 0.9 to 5.3 mass $\%$.

From the agglomeration test of two glass compositions enriched with $\mathrm{Rh}_{2} \mathrm{O}_{3}$ and $\mathrm{RuO}_{2}$, we have learned that even agglomerates of spinel and $\mathrm{RuO}_{2}$ bigger than $100 \mu \mathrm{m}$ slowly settle because of their size and shape configuration. These non-compact agglomerates were composed of particles that were loosely touching each other in all directions, which resulted in high-surface area agglomerate with "holes". The X-ray tomography combined with SEM and image analysis also revealed that the size of agglomerates slowly increased with time and with the distance from the bottom. 


\section{Quality Assurance}

This work was conducted within the Project 51932 Quality Assurance (QA) Plan, developed to be compliant with 10 CFR 830, Subpart A, NQA-1-2004, and DOE Order 414.1C. The Project QA plan meets the requirements of the Fuel Cycle Technology (FCT) Quality Assurance Program Description (QAPD), supports the Pacific Northwest National Laboratory (PNNL) FCT Interface Document, and defines the graded approach for this exploratory and scoping Office of River Protection (ORP) Project.

The specific testing requirements and activities to be performed were defined in the Test Plan. ${ }^{1}$ The Project QA Plan is supported by PNNL standard operating procedures that will be used for this work, defines the requirements for documentation and reviews for activities that support the Project, and are applicable to this testing.

\footnotetext{
${ }^{1}$ HLW-TP-11-01, Rev. 0. 2011. HLW Glass Studies: Development of Crystal-Tolerant HLW Glasses. Pacific Northwest National Laboratory, Test Plan.
} 


\section{Contents}

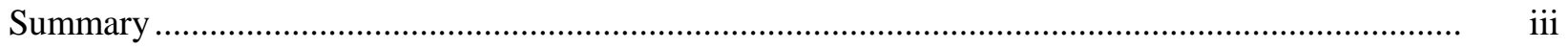

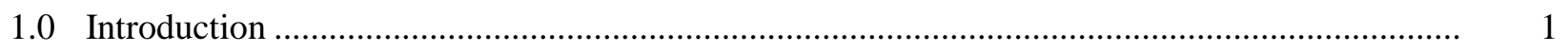

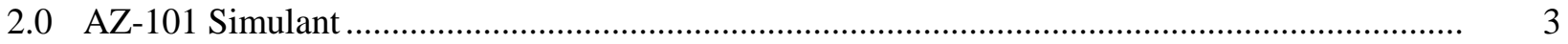

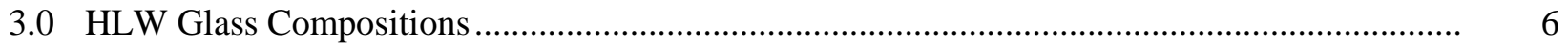

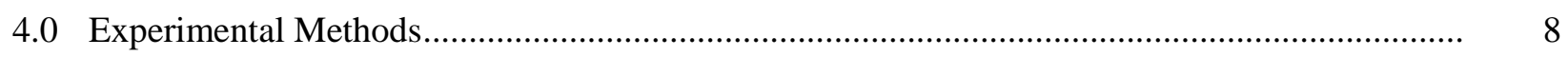

4.1 X-Ray Microfocus Computed Tomography.................................................................. 8

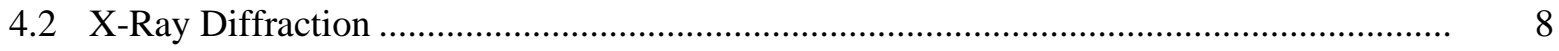

4.3 Scanning Electron Microscopy and Energy Dispersive Spectroscopy ............................... 9

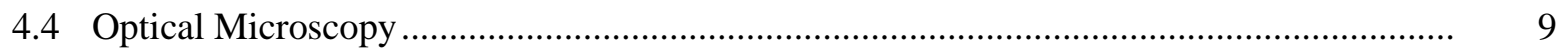

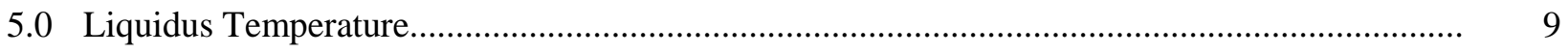

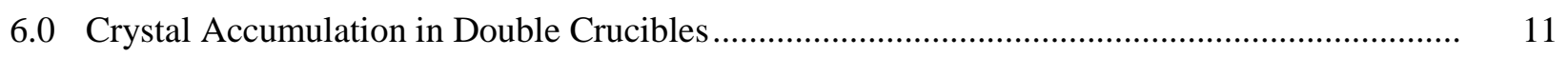

6.1 Crystal Morphology and Size with Optical Microscopy ................................................. 12

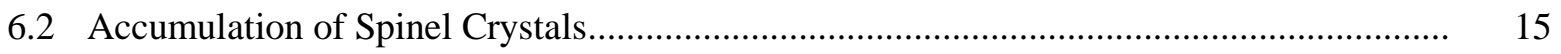

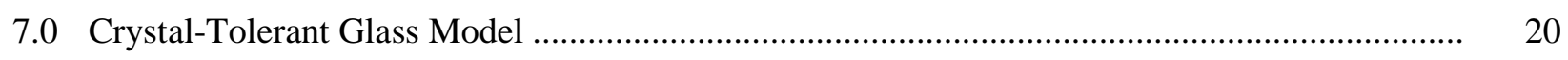

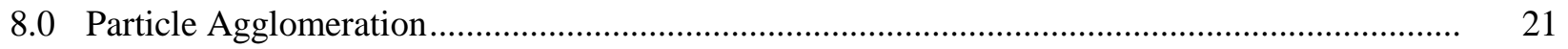

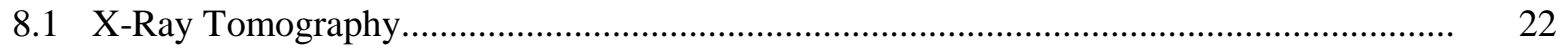

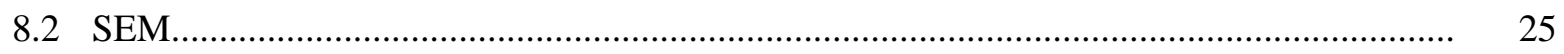

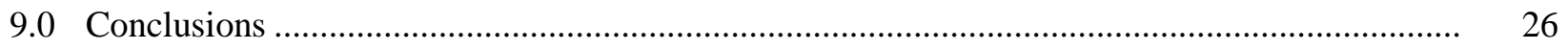

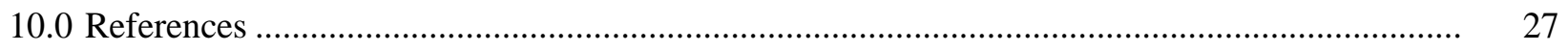




\section{Figures}

1 X-Ray Micro-Focus Tomography System............................................................................

2 Effect of Composition and Temperature on Mass Fraction of Spinel Crystals .......................... 10

3 Cross-Section of Double Crucible Assembly ........................................................................ 12

4 Transmitted-Light Optical Microscope Images of Spinel Crystals in Selected Glasses Heat-Treated at $850^{\circ} \mathrm{C}$ for $\sim 7$ Days: Cr0.3, Ni1.5/Cr0.3, Ni1.29, and Ni1.5/Fe17.5 ................. 13

5 Transmitted-Light Optical Microscope Image of Spinel Crystals in Ni1.5/Ru0.015 Glass Heat-Treated at $850^{\circ} \mathrm{C}$ for 6 Days 19 Hours 5 Minutes............................................................. 13

6 Transmitted-Light Optical Microscope Images of Spinel Crystals in Selected Glasses Heat-Treated at $850^{\circ} \mathrm{C}$ for $\sim 7$ Days: Ni1.5/Al10 and Ni1.5/Li3.8.

7 Transmitted-Light Optical Microscope Images of Spinel Crystals in Previously Tested Glasses Heat-Treated at $850^{\circ} \mathrm{C}$ for Different Times: Ni1.07, Ni1.5, Ni1.5/nm, and $\mathrm{Ni1} .5 / \mathrm{Fe} 20$

8 Thickness of Deposited Spinel Sludge Layer as a Function of Time

9 SEM Images of Accumulated Spinel Layer in the Ni1.5/Fe17.5 Glass After HeatTreatment at $850^{\circ} \mathrm{C}$ for 3 Days 10 Minutes, 3 Days 21 Hours 45 Minutes, 4 Days 21 Hours 20 Minutes, and 7 Days.

10 Transmitted-Light Optical Microscope Images of Spinel Crystals and Hematite in Ni1.5/Fe17.5 Glass Heat-Treated at $850^{\circ} \mathrm{C}$ for 4 Days 21 Hours 20 Minutes.

11 SEM Images of Spinel Layers Deposited at $850^{\circ} \mathrm{C}$ : Ni1.5/Ru0.015 - 6 days 19 hours 5 minutes, Cr0.3 - 7 days, C) Ni1.29 - 6 days 21 hours 35 minutes, and Ni1.5/Cr0.3 7 days

12 SEM Images of Crystals on the Surface of the Thin-Sections for Glasses Heat-Treated at $850^{\circ} \mathrm{C}$ for $\sim 7$ Days: Ni15/Al10 - 6 days 23 hours 40 minutes and Ni1.5/Li3.8 7 days 1 hour.

13 SEM Images of Crystal Clouds Found in the Ni1.5Ru0.087 Glass After 7 Days of Heat-Treatment at $850^{\circ} \mathrm{C}$

14 SEM Image of Accumulated Spinel Layer in the Ni1.5/Cr0.3 Glass After HeatTreatment at $850^{\circ} \mathrm{C}$ for 13 Days and 20 Hours.

15 Calculated vs. Measured Thicknesses of Accumulated Layers for the Glasses Used in the Model Fit and for Ni1.5/Fe17.5 Glass

16 Cross-Section of Testing Assembly

17 X-Ray Tomograph Images of Agglomerates in the XZ Slice in the Middle of the Alumina Crucible for $\mathrm{BL} / \mathrm{RuO}_{2}$ and $\mathrm{Ni} 1.5 / \mathrm{RuO}_{2}$ Glasses Heat-Treated at $850^{\circ} \mathrm{C}$ for 2 Days and 1 Day 21 Hours and 15 Minutes, Respectively

18 X-Ray Tomograph Images of Agglomerates Formed in the Ni1.5/Ru0 ${ }_{2}$ Glass HeatTreated in Alumina Crucible at $850^{\circ} \mathrm{C}$ for 1 Day 21 Hours and 15 Minutes:

$\mathrm{XY}$ slice $1.6 \mathrm{~cm}$ above the bottom and XY slice $2.6 \mathrm{~cm}$ above the bottom

19 Maximum and Average Size of Agglomerates as a Function of the Distance from the Bottom of the Crucible; $\mathrm{BL} / \mathrm{RuO}_{2}$ Glass Heat-Treated at $850^{\circ} \mathrm{C}$ for 2 Days....

20 Maximum and Average Size of Agglomerates as a Function of the Distance from the Bottom of the Crucible; Ni1.5/ $\mathrm{RuO}_{2}$ Glass Heat-Treated at $850^{\circ} \mathrm{C}$ for 1 Day 21 Hours and 15 Minutes. 
21 Agglomeration in the $\mathrm{Ni1} .5 / \mathrm{RuO}_{2}$ Glass Heat-Treated at $850^{\circ} \mathrm{C}$ for 1 Day 21 Hours

15 Minutes, 3 Days 2 Hours 45 Minutes, and 4 Days 5 Minutes

22 Agglomeration in the $\mathrm{BL} / \mathrm{RuO}_{2}$ Glass Heat-Treated at $850^{\circ} \mathrm{C}$ for 2 Days and 3 Days 21 Hours 25 Minutes.

\section{Tables}

1 Composition of HLW AZ-101 Simulant in Mass Fraction of Oxides and Halogens ................... 3

2 Analyzed Composition of AZ-101 Simulant Compared with Target Composition of Simulant from Literature.

3 Analyzed Composition of Previously Used AZ-101 Simulant Compared with Target Composition of Simulant That was Used for This Work.

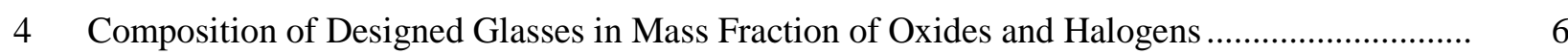

5 Composition of Glasses Used in Agglomeration Study in Mass Fraction of Oxides and

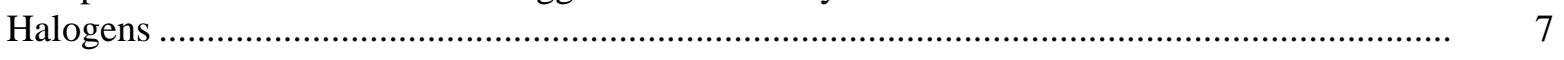

$6 \quad$ Spinel Fitted Parameters and $T_{L}$ 's as Determined with Optical Microscopy .............................. 11

7 Concentration of Spinel in Mass and Volume Percent for Glasses Heat-Treated at

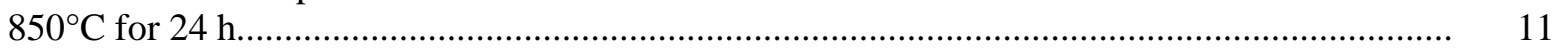

8 Slope and Intercept for Linear Fitted Lines in the Figure 8 …................................................. 15

9 Component Coefficients Calculated with an Empirical Model ................................................. 20 



\subsection{Introduction}

The high-level radioactive waste (HLW) from the Hanford and Savannah River Sites is being vitrified in stable borosilicate glass for long-term storage and disposal. This process is time consuming and expensive because it is highly dependent on loading of HLW in glass and on the rate of HLW glass production. The current HLW melters are projected to operate in an inefficient manner as they are subjected to artificial constraints that limit waste loading to far below its intrinsic level (Kim and Vienna 2002). These constraints, such as liquidus temperature $\left(T_{L}\right)$ of glass or the temperature at which the equilibrium fraction of spinel crystals in the melt is below $1 \mathrm{vol} \%\left(T_{1}\right)$, nominally below $1050^{\circ} \mathrm{C}$, were imposed to prevent clogging of the melter with spinel crystals that can accumulate at the bottom and in the glass discharge riser (Hrma et al. 2003) based upon operational experience with static melters (i.e., non-bubbled).

Matyáš et al. (2001) showed through mathematical modeling that $T_{L}$ has only a little impact on the rate of settling and, in contrast, the crystal size is the main factor determining the rate of accumulation. Therefore, while being conservative and costly, the constraints cannot prevent the formation, growth, and accumulation of spinel crystals in considerably cooler regions $\left(\sim 850^{\circ} \mathrm{C}\right)$ of the glass discharge riser during melter idling. At this temperature, a significant volume of large octahedral crystals of spinel [Fe, Ni, Mn, $\mathrm{Zn}][\mathrm{Fe}, \mathrm{Cr}]_{2} \mathrm{O}_{4}$ can precipitate in the glass (Izak et al. 2001). Matyáš et al. (2010b) demonstrated that these crystals rapidly settle, forming a thick sludge layer with rates up to $0.6 \mathrm{~mm} /$ day. This settling rate is fast enough to form a few $\mathrm{cm}$ thick sludge layer that can partially or completely block the riser during idling, thereby preventing molten glass from discharging during normal operation. This is aggravated by the fact that the spinel sludge cannot be dissolved at low temperatures in the riser and cannot be easily disturbed (Mika et al. 2000, 2002).

To protect the melter from detrimental accumulation of spinel crystals, attention has been focused on the behavior of spinel crystals in HLW borosilicate glasses, such as equilibrium fraction of spinel, spinel crystallization kinetics, spinel settling rate and the rheology of spinel sludge. Stachnik et al. (2000) investigated the equilibrium mass fraction of spinel as a function of the $\mathrm{Fe}, \mathrm{Ni}$, and $\mathrm{Cr}$, indicating that Ni-rich glass precipitated more than three times higher concentration of spinel compared to Fe and Cr-rich glasses. Wilson et al. (2002) went even further by determining the equilibrium mass fraction as a function of temperature and concentration of seven different components (Al, Cr, Fe, $\mathrm{Li}, \mathrm{Mg}, \mathrm{Na}$, and $\mathrm{Ni}$ ). This study confirmed the significant increase in concentration of spinel crystals in Ni-rich glasses and indicated that this increase is augmented by $\mathrm{Fe}, \mathrm{Al}$, and $\mathrm{Mg}$ and mitigated by $\mathrm{Na}$ and Li. Later on Jiricka et al. (2003) studied the phase equilibrium in low-silica HLW glasses with spinel as the primary phase and showed that $T_{L}$ is most increased by $\mathrm{Ni}$ and $\mathrm{Cr}$, but $\mathrm{Cr}$ affected the $T_{L}$ much less than in glasses with higher $\mathrm{SiO}_{2}$ content.

Alton et al. (2002a) focused on experimental measurements of spinel crystallization in 11-component generic HLW glass (MS-7) with $T_{L}=1078^{\circ} \mathrm{C}$ and determined the mass transfer coefficients for dissolution and growth from Hixson-Crowell equation. Izak et al. (2001) investigated the effect of minor components on spinel crystallization during feed-to-glass conversion for the same glass and stated that while $\mathrm{Ag}_{2} \mathrm{O}$ and $\mathrm{CuO}$ did not help nucleate spinel the $\mathrm{RuO}_{2}$ increased the crystal number density $\left(\mathrm{n}_{\mathrm{s}}\right)$ by two orders of magnitude and significantly decreased the crystal size. They also indicated that some submicron spinel from coldcap (feed pile) can be passed into the melt and provide nucleation sites for 
crystallization of spinel in the molten glass. Alton et al. (2002b) followed with a statement that the noble metals ( $\mathrm{Rh}, \mathrm{Ru}, \mathrm{Pd}$, and $\mathrm{Pt}$ ) increased $\mathrm{n}_{\mathrm{s}}$ independently of temperature by up to four orders of magnitude compared with MS-7 baseline glass.

The settling of spinel crystals in molten glasses (Matyáš et al. 2010b; LaMont and Hrma 1998; Kloužek et al. 2001; Matlack et al. 2009) as well as transparent liquids (Matyáš et al. 2011, 2010a) was researched in the laboratory. Lamont and Hrma (1998) observed the parabolic shape of the settling front indicating that the settling crystals generated a convective cell within the melt. Kloužek et al. (2001) determined that the measured settling distances between the glass level and the uppermost crystals in the centerline of the crucible were less than $10 \%$ smaller than the distances calculated with the modified Stoke’s law. Matyáš et al. (2010b) determined the accumulation rate of crystals as a function of spinel forming components and noble metals, and revealed a beneficial effect of suppressing the crystal size and accumulation rate through additions of Fe and noble metals. Matlack et al. reported that the high-crystal content glasses of up to $4.2 \mathrm{vol} \%$ at $950^{\circ} \mathrm{C}$ have been successfully discharged from the DuraMelter ${ }^{\circledR}$ DM-100 after about 8 days of melter idling at $950^{\circ} \mathrm{C}$ (Matlack et al. 2009).

To improve predictions of the accumulation rate, Matyáš et al. (2011) studied the settling of particles in silicone oils with a developed optical particle-dynamics-analyzer, and determined the shape factors for individual spinel crystals and agglomerates. Recently, Matyáš et al. (2010a) determined that the Stokes and Richardson-Zaki equations can be applied to adequately predict the accumulation rate for different concentrations of spinel crystals in the glass discharge riser of HLW melter.

Our long-term objective is to develop an empirical model that can predict the crystal accumulation in the riser as a function of glass composition, providing the guidance to formulate crystal-tolerant glasses for higher waste loading. By keeping the spinel crystals small and therefore limiting spinel deposition in the melter, these glasses will allow high waste loading without decreasing melter lifetime.

The preliminary model developed in FY 2010 performed well $\left(\mathrm{R}^{2}=0.985\right)$ in predicting the thicknesses of accumulated layers as a function of concentration of spinel-forming components in glass (Matyáš et al. 2010a). In addition, the experimental data indicated that 1) the high concentrations of Ni in HLW glasses would result in the formation of large spinel crystals that will produce a thick sludge layer and thereby potentially plug the bottom of the riser, and that 2) the noble metals, Fe, and Al were the components that significantly slowed down or stopped the accumulation of spinel crystals by decreasing the average crystal size through increasing $n_{s}$.

In our study, a series of lab-scale crucible tests were performed on designed glasses of different compositions to further investigate and simulate the effect of $\mathrm{Cr}, \mathrm{Ni}, \mathrm{Fe}, \mathrm{Al}, \mathrm{Li}$, and $\mathrm{RuO}_{2}$ on the accumulation rate of spinel crystals in the glass discharge riser of the HLW melter. The experimental data were used to expand the compositional region covered by an empirical model developed previously (Matyáš et al. 2010b), improving its predictive performance. We also investigated the mechanism for agglomeration of particles and impact of agglomerates on accumulation rate. In addition, the $T_{L}$ was measured as a function of temperature and composition. 


\subsection{AZ-101 Simulant}

A non-radioactive AZ-101 simulant of pretreated HLW from Tank 241-AZ-101 was produced by Noah Technologies Corp. A total of $250 \mathrm{~L}$ of AZ-101 simulant was completely dried at $105^{\circ} \mathrm{C}$, crushed into particle size from 50 to $200 \mu \mathrm{m}$, homogenized in the mixer, and transferred into buckets that were shipped to Pacific Northwest National Laboratory (PNNL). The simulant preparation was conducted in accordance with the quality requirements of the Statement of Work and contract. ${ }^{1}$ Table 1 shows the composition of the simulant which was derived from a combination of actual AZ-101 sludge with a portion of cesium ion exchange concentrate (Eibling et al. 2003). The chemical compositions of the raw materials were converted to oxide and halogen concentrations that will remain in the glass.

Table 1. Composition of HLW AZ-101 Simulant in Mass Fraction of Oxides and Halogens

\begin{tabular}{llllllll}
\hline \multicolumn{2}{c}{ Component } & \multicolumn{2}{c}{ Component } & \multicolumn{2}{c}{ Component } & \multicolumn{2}{c}{ Component } \\
\hline $\mathrm{Al}_{2} \mathrm{O}_{3}$ & 0.2263 & $\mathrm{Fe}_{2} \mathrm{O}_{3}$ & 0.3999 & $\mathrm{Rh}_{2} \mathrm{O}_{3}$ & $\mathrm{NA}$ & $\mathrm{Cl}$ & 0.0006 \\
$\mathrm{~B}_{2} \mathrm{O}_{3}$ & 0.0159 & $\mathrm{~K}_{2} \mathrm{O}$ & 0.0095 & $\mathrm{RuO}_{2}$ & $\mathrm{NA}$ & $\mathrm{Ce}_{2} \mathrm{O}_{3}$ & 0.0056 \\
$\mathrm{BaO}$ & 0.0026 & $\mathrm{MgO}$ & 0.0036 & $\mathrm{SiO}_{2}$ & 0.0467 & $\mathrm{CoO}$ & 0.0003 \\
$\mathrm{CaO}$ & 0.0158 & $\mathrm{MnO}$ & 0.0097 & $\mathrm{SO}_{3}$ & 0.0023 & $\mathrm{CuO}$ & 0.0011 \\
$\mathrm{CdO}$ & 0.0178 & $\mathrm{Na}_{2} \mathrm{O}$ & 0.0786 & $\mathrm{TiO}_{2}$ & 0.0008 & $\mathrm{La}_{2} \mathrm{O}_{3}$ & 0.0061 \\
$\mathrm{Cr}_{2} \mathrm{O}_{3}$ & 0.0047 & $\mathrm{NiO}$ & 0.0175 & $\mathrm{ZnO}$ & 0.0006 & $\mathrm{Nd}_{2} \mathrm{O}_{3}$ & 0.0050 \\
$\mathrm{~F}$ & 0.0002 & $\mathrm{P}_{2} \mathrm{O}_{5}$ & 0.0088 & $\mathrm{ZrO}_{2}$ & 0.1148 & $\mathrm{SnO}_{2}$ & 0.0027 \\
\hline \multicolumn{7}{l}{$\mathrm{NA}=$ Noble metals were not added. } \\
\hline \multicolumn{7}{l}{}
\end{tabular}

A representative sample of dried and ground AZ-101 simulant was sent for analysis of metals to Southwest Research Institute (SWRI) to check an agreement with the target composition from literature and to compare its composition with the previously used AZ-101 simulant (prepared by Optima Chemical Co.). Methods blanks, spikes, and reference glass standards (National Institute for Standards and Technology [NIST] SRM 278 Obsidian Rock and NIST SRM 688 Basalt Rock) were run to access the precision and accuracy of analysis with inductively-coupled plasma-mass spectrometry (ICP-MS) and inductively coupled plasma-atomic emission spectroscopy (ICP-AES).

The simulant was converted into liquid using four techniques: 1) $\mathrm{LiBO}_{2} / \mathrm{Li}_{2} \mathrm{~B}_{4} \mathrm{O}_{7}$ fusion to determine $\mathrm{Al}, \mathrm{Ba}, \mathrm{Ca}, \mathrm{Cr}, \mathrm{Co}, \mathrm{Fe}, \mathrm{Mn}, \mathrm{P}, \mathrm{Si}, \mathrm{Na}, \mathrm{Sn}, \mathrm{Ti}$, and $\mathrm{Zr}$; 2) $\mathrm{HF} / \mathrm{HNO}_{3}$ digestion to determine $\mathrm{Ru}$;

3) $\mathrm{HNO}_{3} / \mathrm{HCl} / \mathrm{HF}$ digestion in closed vessel to determine B and S; and 4) $\mathrm{HNO}_{3} / \mathrm{HClO}_{4} / \mathrm{HF} / \mathrm{HCl}$ digestion in open vessel to determine $\mathrm{Cd}, \mathrm{Cu}, \mathrm{La}, \mathrm{Pb}, \mathrm{Li}, \mathrm{Mg}$, Mo, Ni, K, Rh, and $\mathrm{Zn}$. Produced solutions were analyzed for Co, Rh, Ru, Ti, and Zn with ICP-MS and for all other metals with ICP-AES.

Table 2 compares analyzed composition of the simulant with the composition data from Eibling et al. (2003). The concentrations of all the components were within the specified criteria (based on the levels of accuracy that were accepted in the simulant as originally prepared by Savannah River National Laboratory). The relatively large relative percent differences (RPD) for some components illustrate the impact of analytical errors and small-scale errors introduced during the simulant preparation. Table 3

\footnotetext{
${ }^{1}$ Preparation of the AZ-101 HLW Simulant, RFP No. 117727, 2011.
} 
compares composition of previously used AZ-101 simulant (Optima Chemical Co.) with target composition of simulant (Noah Technologies Corp.) that was used for our study. The concentrations of most components were in a good agreement. Larger but still acceptable differences in RPD of more than $10 \%$ but less than $30 \%$ were observed for $\mathrm{Al}_{2} \mathrm{O}_{3}, \mathrm{Na}_{2} \mathrm{O}, \mathrm{SO}_{3}, \mathrm{ZrO}_{2}$, and $\mathrm{CuO}$.

Table 2. Analyzed Composition of AZ-101 Simulant Compared with Target Composition of Simulant from Literature

\begin{tabular}{|c|c|c|c|c|c|c|}
\hline Component & $\begin{array}{c}\text { AZ-101 } \\
\text { (Eibling et al. 2003) }\end{array}$ & $\begin{array}{c}\text { AZ-101 } \\
\text { (Analyzed) }^{(\mathrm{a})}\end{array}$ & Average & SD & RSD, \% & RPD, \% \\
\hline $\mathrm{Al}_{2} \mathrm{O}_{3}$ & 0.2263 & 0.2022 & 0.2143 & 0.0170 & 8.0 & -10.6 \\
\hline $\mathrm{B}_{2} \mathrm{O}_{3}$ & 0.0159 & 0.0012 & 0.0086 & 0.0104 & 120.9 & -92.5 \\
\hline $\mathrm{BaO}$ & 0.0026 & 0.0019 & 0.0023 & 0.0005 & 21.5 & -26.9 \\
\hline $\mathrm{CaO}$ & 0.0158 & 0.0116 & 0.0137 & 0.0030 & 21.7 & -26.6 \\
\hline $\mathrm{CdO}$ & 0.0178 & 0.0172 & 0.0175 & 0.0004 & 2.4 & -3.4 \\
\hline $\mathrm{Cr}_{2} \mathrm{O}_{3}$ & 0.0047 & 0.0036 & 0.0042 & 0.0008 & 18.5 & -23.4 \\
\hline F & 0.0002 & NA & - & - & - & - \\
\hline $\mathrm{Fe}_{2} \mathrm{O}_{3}$ & 0.3999 & 0.3231 & 0.3615 & 0.0543 & 15.0 & -19.2 \\
\hline $\mathrm{K}_{2} \mathrm{O}$ & 0.0095 & 0.0034 & 0.0065 & 0.0043 & 66.4 & -64.2 \\
\hline $\mathrm{MgO}$ & 0.0036 & 0.0028 & 0.0032 & 0.0006 & 17.7 & -22.2 \\
\hline $\mathrm{MnO}$ & 0.0097 & 0.0078 & 0.0088 & 0.0013 & 15.3 & -19.6 \\
\hline $\mathrm{Na}_{2} \mathrm{O}$ & 0.0786 & 0.0847 & 0.0817 & 0.0043 & 5.3 & 7.8 \\
\hline $\mathrm{NiO}$ & 0.0175 & 0.0131 & 0.0153 & 0.0031 & 20.3 & -25.1 \\
\hline $\mathrm{P}_{2} \mathrm{O}_{5}$ & 0.0088 & 0.0081 & 0.0085 & 0.0005 & 5.8 & -8.0 \\
\hline $\mathrm{Rh}_{2} \mathrm{O}_{3}$ & 0.0009 & 2.5E-07 & - & - & - & - \\
\hline $\mathrm{RuO}_{2}$ & 0.0017 & $1.2 \mathrm{E}-06$ & - & - & - & - \\
\hline $\mathrm{SiO}_{2}$ & 0.0467 & 0.0320 & 0.0394 & 0.0104 & 26.4 & -31.5 \\
\hline $\mathrm{SO}_{3}$ & 0.0023 & 0.0012 & 0.0018 & 0.0008 & 43.2 & -47.8 \\
\hline $\mathrm{TiO}_{2}$ & 0.0008 & 0.0004 & 0.0006 & 0.0003 & 47.1 & -50.0 \\
\hline $\mathrm{ZnO}$ & 0.0006 & 0.0004 & 0.0005 & 0.0001 & 28.3 & -33.3 \\
\hline $\mathrm{ZrO}_{2}$ & 0.1148 & 0.0933 & 0.1041 & 0.0152 & 14.6 & -18.7 \\
\hline $\mathrm{Cl}$ & 0.0006 & NA & - & - & - & - \\
\hline $\mathrm{Ce}_{2} \mathrm{O}_{3}$ & 0.0056 & NA & - & - & - & - \\
\hline $\mathrm{CoO}$ & 0.0003 & 0.0002 & 0.0003 & 0.0001 & 23.6 & -33.3 \\
\hline $\mathrm{CuO}$ & 0.0011 & 0.0008 & 0.0010 & 0.0002 & 21.2 & -27.3 \\
\hline $\mathrm{La}_{2} \mathrm{O}_{3}$ & 0.0061 & 0.0075 & 0.0068 & 0.0010 & 14.6 & 23.0 \\
\hline $\mathrm{Nd}_{2} \mathrm{O}_{3}$ & 0.0050 & NA & - & - & - & - \\
\hline $\mathrm{SnO}_{2}$ & 0.0027 & 0.0040 & 0.0034 & 0.0009 & 27.0 & 48.1 \\
\hline LOI & - & 0.1607 & - & - & - & - \\
\hline Total & 1.0000 & 0.9812 & - & - & - & - \\
\hline \multicolumn{7}{|c|}{$\begin{array}{l}\text { (a) Does not include } 0.0019 \mathrm{PbO}, 9.0 \mathrm{E}-6 \mathrm{Li}_{2} \mathrm{O} \text {, and } 0.0001 \mathrm{MoO}_{3} . \\
-\quad=\text { Empty field. } \\
\mathrm{LOI}=\text { Loss on ignition at } 1000^{\circ} \mathrm{C} . \\
\mathrm{NA}=\text { Not analyzed. } \\
\mathrm{RPD}=\text { Relative percent difference between analyzed and literature compositions. } \\
\mathrm{RSD}=\text { Relative standard deviation (SD/Average) } \\
\mathrm{SD}=\text { Standard deviation. }\end{array}$} \\
\hline
\end{tabular}


Table 3. Analyzed Composition of Previously Used AZ-101 Simulant Compared with Target Composition of Simulant That was Used for This Work

\begin{tabular}{|c|c|c|c|c|c|c|}
\hline Component & $\begin{array}{c}\text { AZ-101 }{ }^{\text {(a) }} \\
\text { (Analyzed) }\end{array}$ & $\begin{array}{c}\text { AZ-101 } \\
\text { (Analyzed) }^{(b)}\end{array}$ & Average & SD & RSD, \% & RPD, \% \\
\hline $\mathrm{Al}_{2} \mathrm{O}_{3}$ & 0.2267 & 0.2022 & 0.2145 & 0.0173 & 8.1 & -10.8 \\
\hline $\mathrm{B}_{2} \mathrm{O}_{3}$ & 0.0012 & 0.0012 & 0.0012 & 0.0000 & 0.0 & 0.0 \\
\hline $\mathrm{BaO}$ & 0.0020 & 0.0019 & 0.0020 & 0.0001 & 3.6 & -5.0 \\
\hline $\mathrm{CaO}$ & 0.0116 & 0.0116 & 0.0116 & 0.0000 & 0.0 & 0.0 \\
\hline $\mathrm{CdO}$ & 0.0185 & 0.0172 & 0.0179 & 0.0009 & 5.1 & -7.0 \\
\hline $\mathrm{Cr}_{2} \mathrm{O}_{3}$ & 0.0038 & 0.0036 & 0.0037 & 0.0001 & 3.8 & -5.3 \\
\hline $\mathrm{Fe}_{2} \mathrm{O}_{3}$ & 0.3224 & 0.3231 & 0.3228 & 0.0005 & 0.2 & 0.2 \\
\hline $\mathrm{K}_{2} \mathrm{O}$ & 0.0035 & 0.0034 & 0.0035 & 0.0001 & 2.0 & -2.9 \\
\hline $\mathrm{MgO}$ & 0.0026 & 0.0028 & 0.0027 & 0.0001 & 5.2 & 7.7 \\
\hline $\mathrm{MnO}$ & 0.0077 & 0.0078 & 0.0078 & 0.0001 & 0.9 & 1.3 \\
\hline $\mathrm{Na}_{2} \mathrm{O}$ & 0.0663 & 0.0847 & 0.0755 & 0.0130 & 17.2 & 27.8 \\
\hline $\mathrm{NiO}$ & 0.0137 & 0.0131 & 0.0134 & 0.0004 & 3.2 & -4.4 \\
\hline $\mathrm{P}_{2} \mathrm{O}_{5}$ & 0.0088 & 0.0081 & 0.0085 & 0.0005 & 5.9 & -8.0 \\
\hline $\mathrm{Rh}_{2} \mathrm{O}_{3}$ & 2.6E-07 & $2.5 \mathrm{E}-07$ & - & - & - & - \\
\hline $\mathrm{RuO}_{2}$ & BRL & $1.2 \mathrm{E}-06$ & - & - & - & - \\
\hline $\mathrm{SiO}_{2}$ & 0.0346 & 0.0320 & 0.0333 & 0.0018 & 5.5 & -7.5 \\
\hline $\mathrm{SO}_{3}$ & 0.0017 & 0.0012 & 0.0015 & 0.0004 & 24.4 & -29.4 \\
\hline $\mathrm{TiO}_{2}$ & 0.0004 & 0.0004 & 0.0004 & 0.0000 & 0.0 & 0.0 \\
\hline $\mathrm{ZnO}$ & 0.0004 & 0.0004 & 0.0004 & 0.0000 & 0.0 & 0.0 \\
\hline $\mathrm{ZrO}_{2}$ & 0.0831 & 0.0933 & 0.0882 & 0.0072 & 8.2 & 12.3 \\
\hline $\mathrm{CoO}$ & 0.0002 & 0.0002 & 0.0002 & 0.0000 & 0.0 & 0.0 \\
\hline $\mathrm{CuO}$ & 0.0009 & 0.0008 & 0.0009 & 0.0001 & 8.3 & -11.1 \\
\hline $\mathrm{La}_{2} \mathrm{O}_{3}$ & 0.0071 & 0.0075 & 0.0073 & 0.0003 & 3.9 & 5.6 \\
\hline $\mathrm{SnO}_{2}$ & 0.0040 & 0.0040 & 0.0040 & 0.0000 & 0.0 & 0.0 \\
\hline LOI & $0.2011^{(\mathrm{c})}$ & $0.1607^{(\mathrm{d})}$ & - & - & - & - \\
\hline Total & 1.0223 & 0.9812 & - & - & - & - \\
\hline $\begin{array}{l}\text { (a) AZ-101 si } \\
\text { preparatio } \\
\text { (b) Does not i } \\
\text { (c) Loss on ig } \\
\text { (d) Loss on ig } \\
\text { B }=\text { Empty } \\
\text { BRL }=\text { Below } \\
\text { LOI }=\text { Loss o } \\
\text { RPD }=\text { Relati } \\
\text { ro work. } \\
\text { RSD }=\text { Relati } \\
\text { SD }=\text { Standa }\end{array}$ & $\begin{array}{l}\text { th supplied by } \\
\text { tyáš et al. } 2010 \\
\text { e } 0.0019 \mathrm{PbO} \text {, } \\
\text { at } 1100^{\circ} \mathrm{C} \text {. } \\
\text { at } 1000^{\circ} \mathrm{C} \text {. } \\
\text { ting limit ( }<1 \text {. } \\
\text { tion. } \\
\text { cent difference } \\
\text { ndard deviation } \\
\text { viation. }\end{array}$ & $\begin{array}{l}\text { 07). } \\
\text { tween compositic } \\
\text { D/Average). }\end{array}$ & $\begin{array}{l}\text { which has be } \\
1 \mathrm{MoO}_{3}\end{array}$ & hat were u & for this an & revious \\
\hline
\end{tabular}




\subsection{HLW Glass Compositions}

Table 4 shows the glass matrix design to study the accumulation rate of spinel crystals. A composition of baseline glass from previous investigations (Matyáš et al. 2010a, 2010b) was varied one or two components-at-a-time while proportionally decreasing the concentration of all other components.

Eight glasses were prepared from AZ-101 simulant and additives $\left(\mathrm{H}_{3} \mathrm{BO}_{3}\right.$, carbonates of $\mathrm{Li}$ and $\mathrm{Na}$, and $\mathrm{SiO}_{2}$ ) according to the PNNL procedure GDL-GBM. ${ }^{1}$ Additional Ni, Al, Cr, Fe, and Li were added as $\mathrm{NiO}, \mathrm{Al}_{2} \mathrm{O}_{3}, \mathrm{Cr}_{2} \mathrm{O}_{3}, \mathrm{Fe}_{2} \mathrm{O}_{3}$, and $\mathrm{Li}_{2} \mathrm{CO}_{3}$. Trace quantities of elemental $\mathrm{Ru}$ (in the form of ruthenium nitrosyl nitrate solution) were added drop by drop to $\mathrm{SiO}_{2}$ that was dispersed on a Petri dish. $\mathrm{SiO}_{2}$ cake was dried in oven at $105^{\circ} \mathrm{C}$ for 1 hour, quenched, and hand-mixed in the plastic bag with the rest of the glass batch. The combined batch for $500 \mathrm{~g}$ of glass was then homogenized in an agate mill for 5 min, melted in $\mathrm{Pt} / 10 \% \mathrm{Rh}$ crucibles in air at $1200^{\circ} \mathrm{C}$ for an hour, air quenched, and ground in a tungsten carbide mill for 2 min. The produced glass powder was remelted under the same conditions, quenched, and a small part used to prepare glass chips for $T_{L}$ testing. Remaining glass was ground in a tungsten carbide mill for 2 min and stored for double crucible test (described below). Six glass batches were prepared for each glass composition.

Table 4. Composition of Designed Glasses in Mass Fraction of Oxides and Halogens

\begin{tabular}{|c|c|c|c|c|c|c|c|c|c|}
\hline Component & $\mathrm{BL}$ & Ni1.29 & Cr0.3 & Ni1.5/Al10 & Ni1.5/Fe17.5 & Ni1.5/Li3.8 & Ni1.5/Cr0.3 & $\mathrm{Ni1.5/Ru0.015^{( \textrm {a } ) }}$ & $\mathrm{Ni1} .5 / \mathrm{Ru} 0.087^{(\mathrm{b})}$ \\
\hline $\mathrm{Al}_{2} \mathrm{O}_{3}$ & 0.0821 & 0.0816 & 0.0820 & 0.1000 & 0.0784 & 0.0799 & 0.0813 & 0.0814 & 0.0813 \\
\hline $\mathrm{B}_{2} \mathrm{O}_{3}$ & 0.0799 & 0.0794 & 0.0798 & 0.0776 & 0.0763 & 0.0777 & 0.0791 & 0.0792 & 0.0791 \\
\hline $\mathrm{BaO}$ & 0.0009 & 0.0009 & 0.0009 & 0.0009 & 0.0009 & 0.0009 & 0.0009 & 0.0009 & 0.0009 \\
\hline $\mathrm{CaO}$ & 0.0057 & 0.0057 & 0.0057 & 0.0055 & 0.0054 & 0.0055 & 0.0056 & 0.0057 & 0.0056 \\
\hline $\mathrm{CdO}$ & 0.0065 & 0.0065 & 0.0065 & 0.0063 & 0.0062 & 0.0063 & 0.0064 & 0.0064 & 0.0064 \\
\hline $\mathrm{Cr}_{2} \mathrm{O}_{3}$ & 0.0017 & 0.0017 & 0.0030 & 0.0017 & 0.0016 & 0.0017 & 0.0030 & 0.0017 & 0.0017 \\
\hline F & 0.0001 & 0.0001 & 0.0001 & 0.0001 & 0.0001 & 0.0001 & 0.0001 & 0.0001 & 0.0001 \\
\hline $\mathrm{Fe}_{2} \mathrm{O}_{3}$ & 0.1451 & 0.1441 & 0.1448 & 0.1408 & 0.1750 & 0.1410 & 0.1436 & 0.1437 & 0.1436 \\
\hline $\mathrm{K}_{2} \mathrm{O}$ & 0.0034 & 0.0034 & 0.0034 & 0.0033 & 0.0032 & 0.0033 & 0.0034 & 0.0034 & 0.0034 \\
\hline $\mathrm{Li}_{2} \mathrm{O}$ & 0.0199 & 0.0198 & 0.0199 & 0.0193 & 0.0190 & 0.0380 & 0.0197 & 0.0197 & 0.0197 \\
\hline $\mathrm{MgO}$ & 0.0013 & 0.0013 & 0.0013 & 0.0013 & 0.0012 & 0.0013 & 0.0013 & 0.0013 & 0.0013 \\
\hline $\mathrm{MnO}$ & 0.0035 & 0.0035 & 0.0035 & 0.0034 & 0.0033 & 0.0034 & 0.0035 & 0.0035 & 0.0035 \\
\hline $\mathrm{Na}_{2} \mathrm{O}$ & 0.1866 & 0.1853 & 0.1864 & 0.1812 & 0.1781 & 0.1814 & 0.1847 & 0.1849 & 0.1847 \\
\hline $\mathrm{NiO}$ & 0.0064 & 0.0129 & 0.0064 & 0.0150 & 0.0150 & 0.0150 & 0.0150 & 0.0150 & 0.0150 \\
\hline $\mathrm{P}_{2} \mathrm{O}_{5}$ & 0.0032 & 0.0032 & 0.0032 & 0.0031 & 0.0031 & 0.0031 & 0.0032 & 0.0032 & 0.0032 \\
\hline $\mathrm{SiO}_{2}$ & 0.4031 & 0.4003 & 0.4025 & 0.3913 & 0.3847 & 0.3920 & 0.3989 & 0.3994 & 0.3991 \\
\hline $\mathrm{SO}_{3}$ & 0.0008 & 0.0008 & 0.0008 & 0.0008 & 0.0008 & 0.0008 & 0.0008 & 0.0008 & 0.0008 \\
\hline $\mathrm{TiO}_{2}$ & 0.0003 & 0.0003 & 0.0003 & 0.0003 & 0.0003 & 0.0003 & 0.0003 & 0.0003 & 0.0003 \\
\hline $\mathrm{ZnO}$ & 0.0002 & 0.0002 & 0.0002 & 0.0002 & 0.0002 & 0.0002 & 0.0002 & 0.0002 & 0.0002 \\
\hline $\mathrm{ZrO}_{2}$ & 0.0416 & 0.0413 & 0.0415 & 0.0404 & 0.0397 & 0.0405 & 0.0412 & 0.0412 & 0.0412 \\
\hline $\mathrm{Cl}$ & 0.0002 & 0.0002 & 0.0002 & 0.0002 & 0.0002 & 0.0002 & 0.0002 & 0.0002 & 0.0002 \\
\hline $\mathrm{Ce}_{2} \mathrm{O}_{3}$ & 0.0020 & 0.0020 & 0.0020 & 0.0019 & 0.0019 & 0.0019 & 0.0020 & 0.0020 & 0.0020 \\
\hline $\mathrm{CoO}$ & 0.0001 & 0.0001 & 0.0001 & 0.0001 & 0.0001 & 0.0001 & 0.0001 & 0.0001 & 0.0001 \\
\hline $\mathrm{CuO}$ & 0.0004 & 0.0004 & 0.0004 & 0.0004 & 0.0004 & 0.0004 & 0.0004 & 0.0004 & 0.0004 \\
\hline
\end{tabular}

\footnotetext{
${ }^{1}$ GDL-GBM, Rev. 3. 2003. Glass Batching and Melting. Pacific Northwest National Laboratory, Technical Procedure.
} 
Table 4. (contd)

\begin{tabular}{|c|c|c|c|c|c|c|c|c|c|}
\hline Component & BL & Ni1.29 & Cr0.3 & Ni1.5/Al10 & Ni1.5/Fe17.5 & Ni1.5/Li3.8 & Ni1.5/Cr0.3 & $\mathrm{Ni1.5/Ru0.015^{( \textrm {a } ) }}$ & $\mathrm{Ni1} .5 / \mathrm{Ru} 0.087^{(\mathrm{b})}$ \\
\hline $\mathrm{La}_{2} \mathrm{O}_{3}$ & 0.0022 & 0.0022 & 0.0022 & 0.0021 & 0.0021 & 0.0021 & 0.0022 & 0.0022 & 0.0022 \\
\hline $\mathrm{Nd}_{2} \mathrm{O}_{3}$ & 0.0018 & 0.0018 & 0.0018 & 0.0017 & 0.0017 & 0.0018 & 0.0018 & 0.0018 & 0.0018 \\
\hline $\mathrm{SnO}_{2}$ & 0.0010 & 0.0010 & 0.0010 & 0.0010 & 0.0010 & 0.0010 & 0.0010 & 0.0010 & 0.0010 \\
\hline Total & 1.0000 & 1.0000 & 1.0000 & 1.0000 & 1.0000 & 1.0000 & 1.0000 & 0.9996 & 0.9988 \\
\hline
\end{tabular}

(a) Added 1.5E-4 $\mathrm{RuO}_{2}$ and $3 \mathrm{E}-4 \mathrm{Rh}_{2} \mathrm{O}_{3}$.

(b) Added 8.7E-4 $\mathrm{RuO}_{2}$ and $3 \mathrm{E}-4 \mathrm{Rh}_{2} \mathrm{O}_{3}$.

Table 5 shows the glass compositions to test particle agglomeration. A composition of baseline and high-Ni glasses from previous investigations (Matyáš et al. 2010a, 2010b) was altered one-at-a-time to accommodate $0.29 \mathrm{wt} \%$ of $\mathrm{RuO}_{2}$. These glasses were prepared following the same procedure as the glasses for crystal accumulation study. Trace quantities of elemental Ru was added in the form of ruthenium nitrosyl nitrate solution, $\mathrm{Rh}$ as $\mathrm{Rh}_{2} \mathrm{O}_{3}$, and additional $\mathrm{Ni}$ for high-Ni glass as $\mathrm{NiO}$. The batch size was $\sim 80 \mathrm{~mL}$ of glass. This volume was sufficient to fill up the testing assembly (Figure 16) and allowed us to keep the concentration of noble metal particles in the glass about the same in every assembly. Eight glass batches were prepared for each glass composition.

Table 5. Composition of Glasses Used in Agglomeration Study in Mass Fraction of Oxides and Halogens

\begin{tabular}{ccc}
\hline Component & $\mathrm{BL} / \mathrm{RuO}_{2}$ & $\mathrm{Ni} 1.5 / \mathrm{RuO}_{2}$ \\
\hline $\mathrm{Al}_{2} \mathrm{O}_{3}$ & 0.0819 & 0.0812 \\
$\mathrm{~B}_{2} \mathrm{O}_{3}$ & 0.0797 & 0.0790 \\
$\mathrm{BaO}$ & 0.0009 & 0.0009 \\
$\mathrm{CaO}$ & 0.0057 & 0.0056 \\
$\mathrm{CdO}$ & 0.0065 & 0.0064 \\
$\mathrm{Cr}_{2} \mathrm{O}_{3}$ & 0.0017 & 0.0017 \\
$\mathrm{~F}$ & 0.0001 & 0.0001 \\
$\mathrm{Fe}_{2} \mathrm{O}_{3}$ & 0.1446 & 0.1433 \\
$\mathrm{~K}_{2} \mathrm{O}$ & 0.0034 & 0.0034 \\
$\mathrm{Li}_{2} \mathrm{O}$ & 0.0198 & 0.0197 \\
$\mathrm{MgO}^{\mathrm{MnO}}$ & 0.0013 & 0.0013 \\
$\mathrm{Na}_{2} \mathrm{O}$ & 0.0035 & 0.0035 \\
$\mathrm{NiO}_{\mathrm{P}_{2} \mathrm{O}_{5}}$ & 0.1860 & 0.1844 \\
$\mathrm{Rh}_{2} \mathrm{O}_{3}$ & 0.0064 & $\mathbf{0 . 0 1 5 0}$ \\
$\mathrm{RuO}_{2}$ & 0.0032 & 0.0032 \\
$\mathrm{SiO}_{2}$ & $\mathbf{0 . 0 0 2 9}$ & $\mathbf{0 . 0 0 2 9}$ \\
$\mathrm{SO}_{3}$ & 0.4018 & 0.3983 \\
$\mathrm{TiO}_{2}$ & 0.0008 & 0.0008 \\
$\mathrm{ZnO}_{\mathrm{ZrO}_{2}}$ & 0.0003 & 0.0003 \\
$\mathrm{Cl}_{\mathrm{Ce}_{2} \mathrm{O}_{3}}$ & 0.0002 & 0.0002 \\
$\mathrm{CoO}_{\mathrm{CuO}}$ & 0.0415 & 0.0411 \\
$\mathrm{La}_{2} \mathrm{O}_{3}$ & 0.0002 & 0.0002 \\
$\mathrm{Nd}_{2} \mathrm{O}_{3}$ & 0.0020 & 0.0020 \\
$\mathrm{SnO}_{2}$ & 0.0010 & 0.0001 \\
$\mathrm{Total}$ & $\mathbf{1 . 0 0 0 0}$ & $\mathbf{1 . 0 0 0 0}$ \\
\hline & & 0.0004 \\
\hline
\end{tabular}




\subsection{Experimental Methods}

Various instruments and experimental techniques were used to elucidate the effect of spinel forming components, alumina, lithium oxide, and noble metals on the accumulation rate, and to study particle agglomeration and its effect on the settling rate.

\subsection{X-Ray Microfocus Computed Tomography}

$\mathrm{X}$-ray microfocus computed tomography, which is more commonly known as computed tomography (CT), is a non-destructive imaging technique used to examine internal structures of geologic and manmade materials. Various forms of this imaging technique have been utilized by the medical industry since 1972 and CT imaging is currently an essential part of patient diagnostics (Kalender 2000). In recent years, scientists have used these systems to investigate geologic materials, with the technology rapidly becoming a part of routine sample characterization (Ketcham and Carlson 2001). For example, imaging with X-rays supported studies of site remediation for heavy metal contaminants and in the evaluation of bulk vitrification processing of low-level tank waste (McGrail et al. 2003; Wellman et al. 2005).

Major components of the CT system include a flat panel detector, rotating stage, and an X-ray tube capable of high resolution and high magnification. Initially, 2D cross-sectional images of an object are generated based on density variations. For example, water and gas filled voids (low density) are easily distinguished within geologic sediment or sludges (high density). The object is rotated in the X-ray beam in a $360^{\circ}$ continuous rotation collecting a designated number of images for each degree of rotation. Each sequential image contains a detailed map of the interior features of the object. After image acquisition, reconstruction of the data and image correction, the real time volume is rendered and 3D visualized.

The CT system is a North Star Imaging (NSI) X-View Digital X-ray Imaging and Microfocus Computed Tomography system manufactured by NSI, Inc. (Rogers, Minnesota). The system, shown in Figure 1, is housed in an 8000 pound lead-lined near-zero-emission enclosure and mounted on a leveling table. X-rays are generated by a microfocus X-ray source (Comet Fienfocus model $160.48160 \mathrm{kV}$ ) and image collection is by a PaxScan ${ }^{\circledR} 2520 \mathrm{~V}$ flat panel digital x-ray detector (pixel pitch of 127 micron and a total active imaging area of $8 \times 10$ inches). The sample stage is equipped with a 150 -mm diameter turntable ( $360^{\circ}$ continuous rotation) and is capable of $150 \mathrm{~mm}$ vertical travel and can be positioned between the detector and x-ray source to optimize the field of view. Depending on instrument parameters, the system is capable of achieving a spatial resolution of $>6 \mu \mathrm{m}$ (in the focal plane) on an object $6.75 \mathrm{~mm}$ in diameter. This resolution decreases with the size of the sample.

\subsection{X-Ray Diffraction}

Glass samples were ground for $2 \mathrm{~min}$ in a tungsten carbide mill. Approximately $1 \mathrm{~g}$ of sample powder was mixed with 5 mass\% of internal standard $\left(\mathrm{CaF}_{2}\right)$ for $1 \mathrm{~min}$ in a tungsten carbide mill, mounted in an X-ray diffraction (XRD) sample holder, and scanned with an X-ray diffractometer Bruker D8 Advanced from Bruker AXS (Madison, WI) equipped with a $\mathrm{Cu} \mathrm{K} \alpha$ target set to a power level of $40 \mathrm{kV}$ and $40 \mathrm{~mA}$. The detector is a position-sensitive detector with an angler range of $3^{\circ} 2 \theta$. The scan parameters were $0.03^{\circ} 2-\theta$ step size, 4 seconds dwell time, and 5 to $70^{\circ} 2-\theta$ scan range. The detection limit of XRD for spinel was 0.1 mass\%. Jade and RIQAS 3.1 software were used to identify 
crystalline phases and to determine their concentration in analyzed samples following the PNNL procedure Glass Development Laboratory (GDL)-XRD. ${ }^{1}$

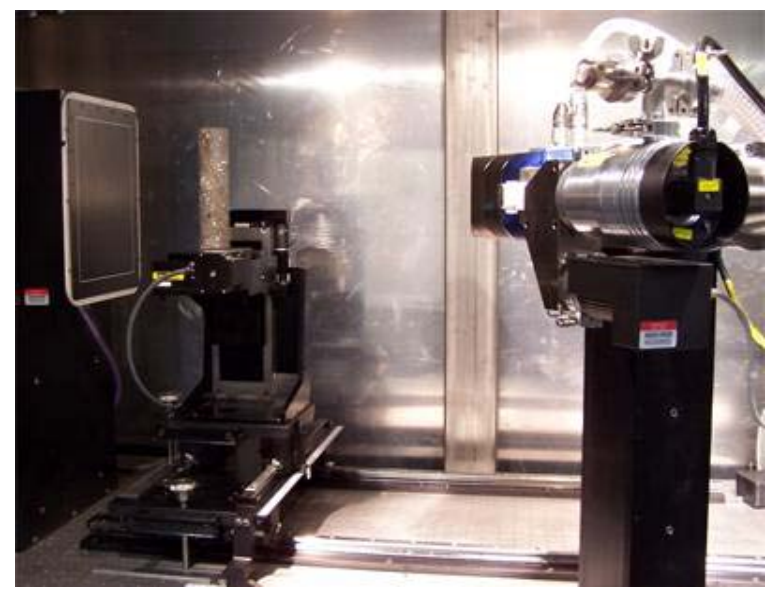

Figure 1. X-Ray Micro-Focus Tomography System

\subsection{Scanning Electron Microscopy and Energy Dispersive Spectroscopy (SEM-EDS)}

Thin sections of selected glass samples were sputter-coated with Au/Pd and analyzed with a JEOL JSM-5900 from SEMTech Solutions Inc. (North Billerica, Massachusetts) equipped with EDAX Li-drifted Si detector. The working distance was $\sim 12 \mathrm{~mm}$, the voltage $15 \mathrm{kV}$, and the beam spot size of a few micrometers.

\subsection{Optical Microscopy}

Thin sections of samples were analyzed with a stereo microscope (magnification range from $10 \times$ to $70 \times$ ) or high-magnification microscope with up to $1000 \times$ magnification under reflective or transmitted light. The size and surface fraction of spinel crystals in selected samples was determined with an imageanalysis program Clemex $3.0^{\circledR}$.

\subsection{Liquidus Temperature}

The liquidus temperature of designed glasses was obtained through heat-treatments at selected temperatures for $24 \mathrm{~h}$ in $\mathrm{Pt} / 10 \% \mathrm{Rh}$ boxes with tight fitting lids (to avoid volatility) in accordance with the PNNL procedure GDL-LQT. ${ }^{2}$ Two glass samples were produced for each temperature. First sample was analyzed with a high-magnification optical microscope for the presence of crystals and the second with an

\footnotetext{
${ }^{1}$ GDL-XRD, Rev. 1. 2007. Quantitative and Semi-quantitative Analysis using X-Ray Diffraction. Pacific Northwest National Laboratory, Technical Procedure.

${ }^{2}$ GDL-LQT, Rev. 4. 2007. Standard Test Methods for Determining the Liquidus Temperature $\left(T_{L}\right)$ of Waste Glasses and Simulated Waste Glasses. Pacific Northwest National Laboratory, Technical Procedure.
} 
$\mathrm{XRD}$ for the spinel content. The liquidus temperature was determined within $6^{\circ} \mathrm{C}$ of the temperature range between the highest and the lowest temperature at which a sample contains or does not contain spinel crystals in the glass, respectively.

The XRD mass fraction of spinel, $C_{0}$, as a function of temperature for tested glasses is shown in Figure 2. If we assume that the fraction of spinel at $\mathrm{T} \geq 850^{\circ} \mathrm{C}$ and $\mathrm{t} \geq 24 \mathrm{~h}$ no longer changes with time, we can use Eq. (1) to fit the XRD data:

$$
C_{0}=C_{\max }\left\{1-\exp \left[-B_{L}\left(\frac{1}{T}-\frac{1}{T_{L}}\right)\right]\right\}
$$

where $B_{L}$ and $C_{\max }$ are composition-dependent coefficients, $T$ is the temperature, and $T_{L}$ is the liquidus temperature; $C_{\max }$ can be interpreted as the hypothetical total (crystalline and dissolved) spinel in glass and $B_{L}$ represents the rate of change of $C_{0}$ at $T=T_{L}$. Table 6 shows fitted parameters in Eq. (1) and liquidus temperatures as determined with optical microscopy for different glasses. The calculated $T_{L}$ 's agreed well with the measured ones. The small discrepancy in $T_{L}$ 's can be explained by the scatter of XRD data. The $T_{L}$ (as determined with optical microscopy) for previously measured Ni1.5 glass was $1080^{\circ} \mathrm{C}$ (Matyáš et al. 2010a, 2010b). Adding $\mathrm{Li}_{2} \mathrm{O}$, or $\mathrm{Cr}_{2} \mathrm{O}_{3}$, or $\mathrm{Al}_{2} \mathrm{O}_{3}$ to this glass decreased $T_{L}$ to $1004^{\circ} \mathrm{C}, 1018^{\circ} \mathrm{C}$, and $1075^{\circ} \mathrm{C}$, respectively. In contrast, adding 0.015 mass $\%$ of $\mathrm{RuO}_{2}$ or 3.12 mass \% of $\mathrm{Fe}_{2} \mathrm{O}_{3}$ increased the $T_{L}$ to $1087^{\circ} \mathrm{C}$ and $1105^{\circ} \mathrm{C}$, respectively. Not surprisingly, introduction of more $\mathrm{RuO}_{2}$ (0.087 mass\%) to Ni1.5 glass did not change the $T_{L}\left(1085^{\circ} \mathrm{C}\right)$.

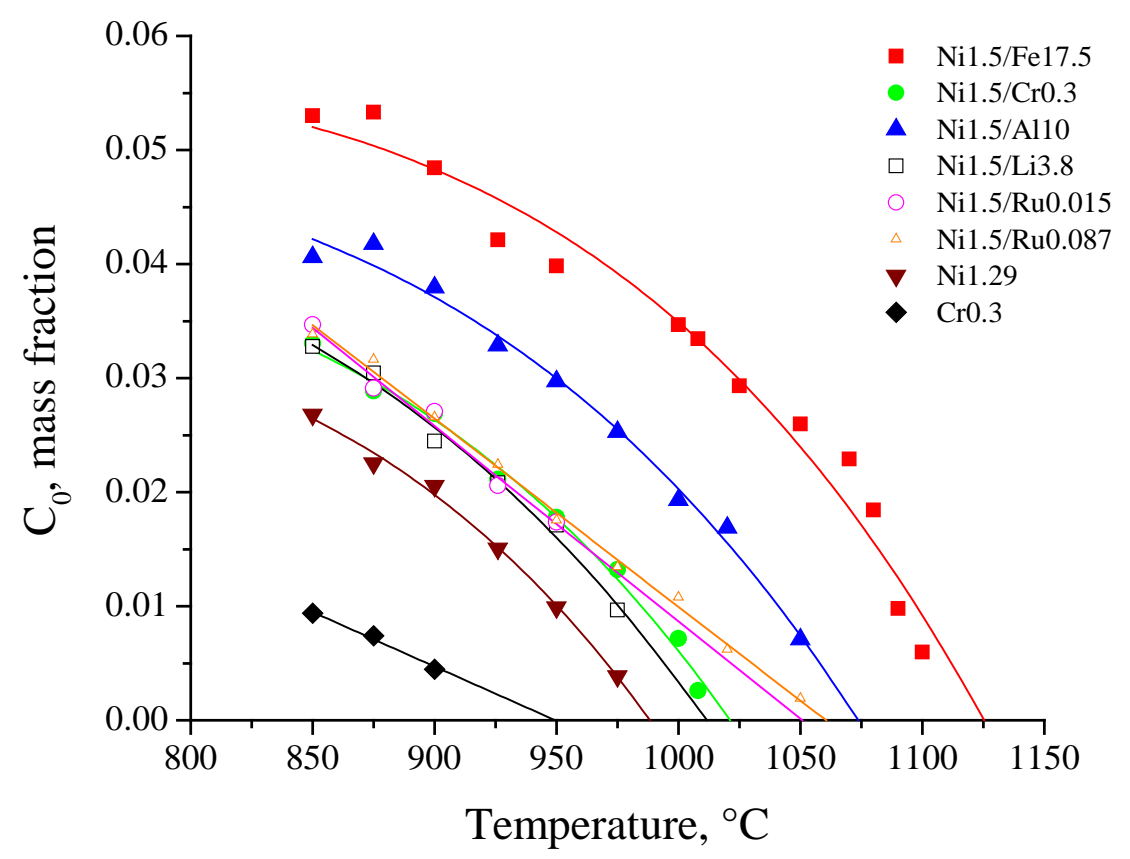

Figure 2. Effect of Composition and Temperature on Mass Fraction of Spinel Crystals. The lines were fitted with Eq. (1). 
Table 6. Spinel Fitted Parameters $\left(C_{\max }, B_{L}, T_{L}\right)$ and $T_{L}$ 's as Determined with Optical Microscopy

\begin{tabular}{lcrcc}
\hline Glass ID & $C_{\max }$, Mass Fraction & $B_{L}, \mathrm{~K}$ & $T_{L},{ }^{\circ} \mathrm{C}^{(\mathrm{a})}$ & $T_{L},{ }^{\circ} \mathrm{C}^{(\mathrm{b})}$ \\
\hline Cr0.3 & 0.0665 & 2126 & 949 & 950 \\
Ni1.29 & 0.0373 & 12633 & 988 & 1005 \\
Ni1.5/Al10 & 0.0513 & 11687 & 1074 & 1075 \\
Ni1.5/Fe17.5 & 0.0578 & 13175 & 1125 & 1105 \\
Ni1.5/Li3.8 & 0.0480 & 10344 & 1012 & 1004 \\
Ni1.5/Cr0.3 & 0.0433 & 11725 & 1021 & 1018 \\
Ni1.5/Ru0.015 & 0.1291 & 2295 & 1051 & 1087 \\
Ni1.5/Ru0.087 & 0.1188 & 2452 & 1061 & 1085
\end{tabular}

(a) Liquidus temperatures obtained from fitting of Eq. (1).

(b) Liquidus temperatures obtained from optical microscopy.

Table 7 summarizes mass and volume concentrations of spinel crystals in the glasses heat-treated at $850^{\circ} \mathrm{C}$ for $24 \mathrm{~h}$. More than 3 mass \% (> $1.5 \mathrm{vol} \%$ ) of crystals formed in all the glasses except for Cr0.3 (0.9 mass\%) and Ni1.29 (2.7 mass\%). The high concentration of spinel, 5.3 mass\%, in the Ni1.5/Fe17.5 glass is the result of supplying additional $\mathrm{Fe}_{2} \mathrm{O}_{3}$ for spinel nucleation and growth.

Table 7. Concentration of Spinel in Mass $\left(C_{0}\right)$ and Volume $\left(V_{0}\right)$ Percent for Glasses Heat-Treated at $850^{\circ} \mathrm{C}$ for $24 \mathrm{~h}$

\begin{tabular}{lcc}
\hline \multicolumn{1}{c}{ Glass ID } & $C_{0}$, mass $\%$ & $V_{0}$, vol\% $^{(\mathrm{a})}$ \\
\hline Cr0.3 & 0.9 & 0.5 \\
Ni1.29 & 2.7 & 1.4 \\
Ni1.5/Al10 & 4.1 & 2.1 \\
Ni1.5/Fe17.5 & 5.3 & 2.7 \\
Ni1.5/Li3.8 & 3.3 & 1.7 \\
Ni1.5/Cr0.3 & 3.3 & 1.7 \\
Ni1.5/Ru0.015 & 3.5 & 1.8 \\
Ni1.5/Ru0.087 & 3.4 & 1.7 \\
\hline
\end{tabular}

(a) For $C_{0}\left\langle\left\langle 1\right.\right.$, the volume percent of spinel is $V_{0} \cong C_{0} \rho_{g} / \rho_{s}$, where $\rho_{g}$ is the glass density $\left(2.7 \times 10^{3} \mathrm{~kg} / \mathrm{m}^{3}\right)$ and $\rho_{s}$ is the spinel density $\left(5.3 \times 10^{3} \mathrm{~kg} / \mathrm{m}^{3}\right)$.

\subsection{Crystal Accumulation in Double Crucibles}

Figure 3 shows the cross-section of the double-crucible assembly. In the double-crucible test, the alumina crucible was nested in a larger silica crucible and covered with molten glass to eliminate Marangoni convection in the meniscus and bubble generation at the bottom of silica crucibles (undisturbed settling) (Matyáš et al. 2010a, 2010b). The core-drilled second silica crucible held the alumina crucible in place and filled up the space, saving more than $0.5 \mathrm{~kg}$ of glass per test. To minimize the effect of the surface crystallization and to eliminate the impact of temperature history on crystal 
nucleation and growth, powdered glass was melted in a Pt-crucible at $1200^{\circ} \mathrm{C}$ for 1 hour. The crucible was then removed from the melting furnace, and molten glass poured into three double crucibles that were rested inside the furnace at $850^{\circ} \mathrm{C}$, mimicking the temperature in the glass discharge riser. Doublecrucibles were removed at various times, air quenched, and cross-sectioned. The red-marked rectangular piece shown in Figure 3 was cut out from the crucibles, thin-sectioned, and analyzed with optical microscopy, SEM-EDS and Clemex Image Analysis Software to determine the thickness of the spinel sludge layer and the size and surface fraction of spinel crystals in the accumulated layers.

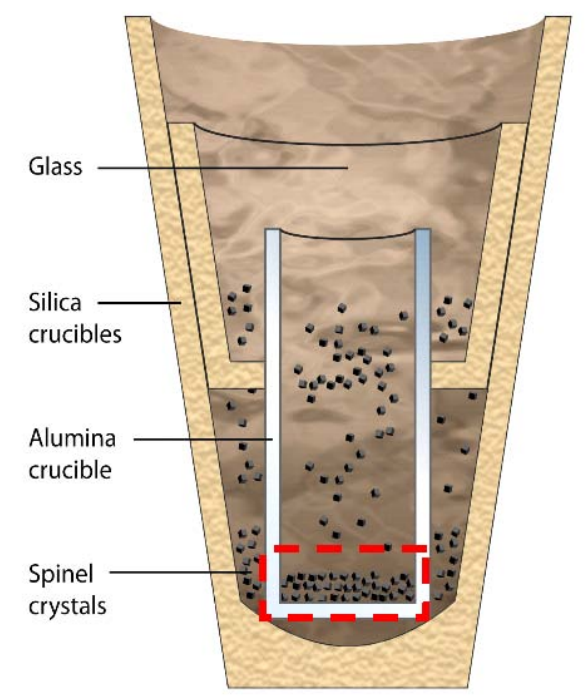

Figure 3. Cross-Section of Double Crucible Assembly (red-marked area shows the location of thinsectioned samples)

\subsection{Crystal Morphology and Size with Optical Microscopy}

Figure 4, 5, and 6 show optical images of spinel crystals above the accumulated layer for selected glasses after double crucible test at $850^{\circ} \mathrm{C}$ for $\sim 7$ days. Well separated crystals with an average size $\sim 80 \mu \mathrm{m}$ formed in the high-chromium glass (Cr0.3), Figure 4A. In contrast, large agglomerates bigger than $130 \mu \mathrm{m}$ formed in the high-nickel (Ni1.29) and high-nickel-chromium (Ni1.5/Cr0.3) glasses, Figures 4B and $\mathrm{C}$, respectively. The agglomeration was even more pronounced in the high-nickel-iron (Ni1.5/Fe17.5) glass, Figure 4D, because of the crystallization of larger number of crystals. Figure 5 illustrates the effect of addition of $\mathrm{RuO}_{2}$ (added as ruthenium nitrosyl nitrate) to the high-nickel glass (Ni1.5) on the size and number density of crystals. A large number of micrometer-sized spinel crystals formed in the Ni1.5/Ru0.015 glass. Figure 6 shows the spinel crystals that formed in the high-nickelaluminum (Ni1.5/Al10) and high-nickel-lithium (Ni1.5/Li3.8) glasses, Figures 6A and B, respectively. Additions of aluminum and lithium to Ni1.5 glass slowed down the growth of individual crystals but promoted the formation of a continuous dendritic network of large needle-like spinel structures.

The effect of $\mathrm{NiO}$ and noble metals on the crystal morphology agreed well with the experimentally observed morphologies shown in the Figure 7 for previously tested glasses (Matyáš et al. 2010a, 2010b). Figure 7 shows optical images of crystals in two high-nickel glasses Ni1.07 and Ni1.5 (Figure 7A and B), high-nickel glass Ni1.5/nm containing 0.03 mass\% of $\mathrm{Rh}_{2} \mathrm{O}_{3}$ and 2.9E-03 mass\% of $\mathrm{RuO}_{2}$ (Figure 7C), 
and high-nickel-iron glass Ni1.5/Fe20 (Figure 7D). Interestingly, an increase in iron oxide concentration in Ni1.5/Fe17.5 glass from 17.5 mass\% to 20 mass \% resulted in the formation of similar large needlelike structures observed after adding extra aluminum or lithium to Ni1.5 glass.

A

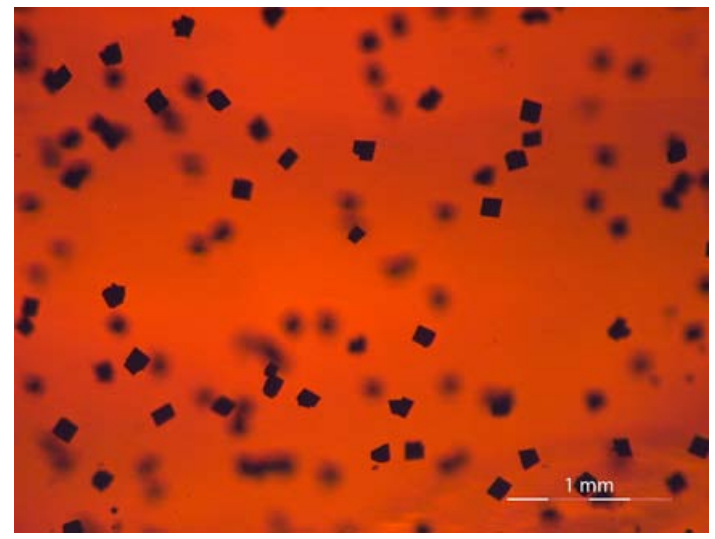

C

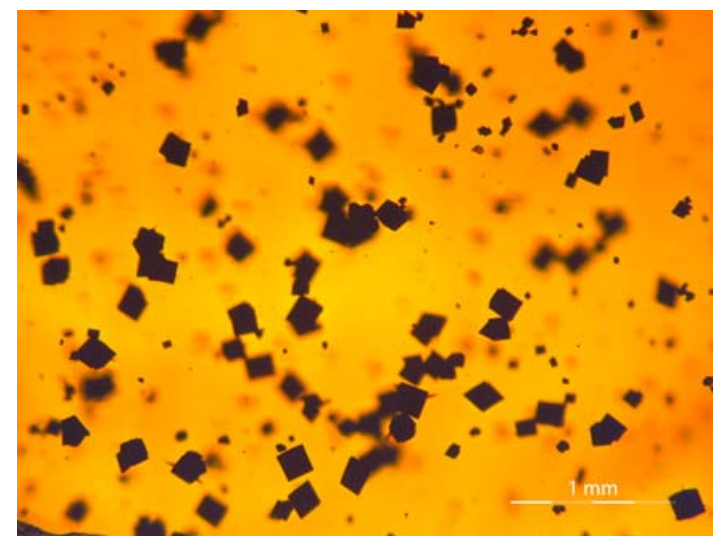

B

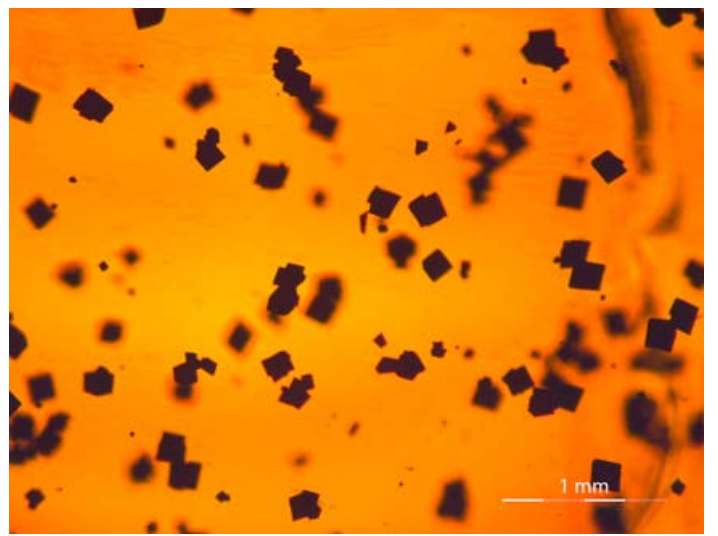

$\mathrm{D}$

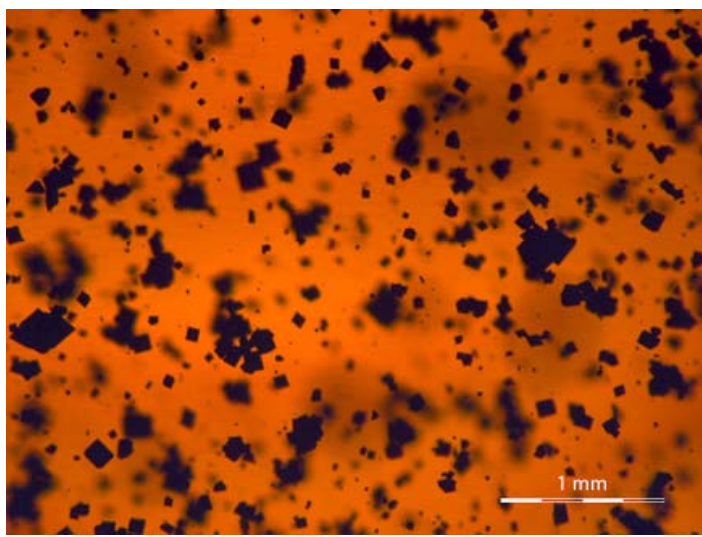

Figure 4. Transmitted-Light Optical Microscope Images of Spinel Crystals in Selected Glasses HeatTreated at $850^{\circ} \mathrm{C}$ for $\sim 7$ Days: A) Cr0.3 (7 days), B) Ni1.5/Cr0.3 (7 days), C) Ni1.29 (6 days 21 hours 35 minutes), and D) Ni1.5/Fe17.5 (7 days 1 hour)

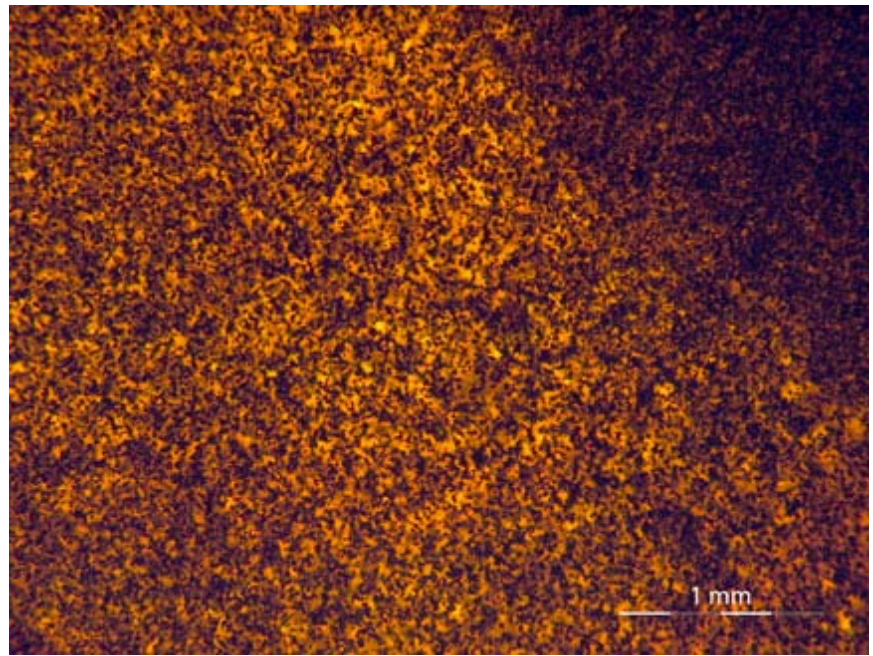

Figure 5. Transmitted-Light Optical Microscope Image of Spinel Crystals in Ni1.5/Ru0.015 Glass HeatTreated at $850^{\circ} \mathrm{C}$ for 6 Days 19 Hours 5 Minutes 
A

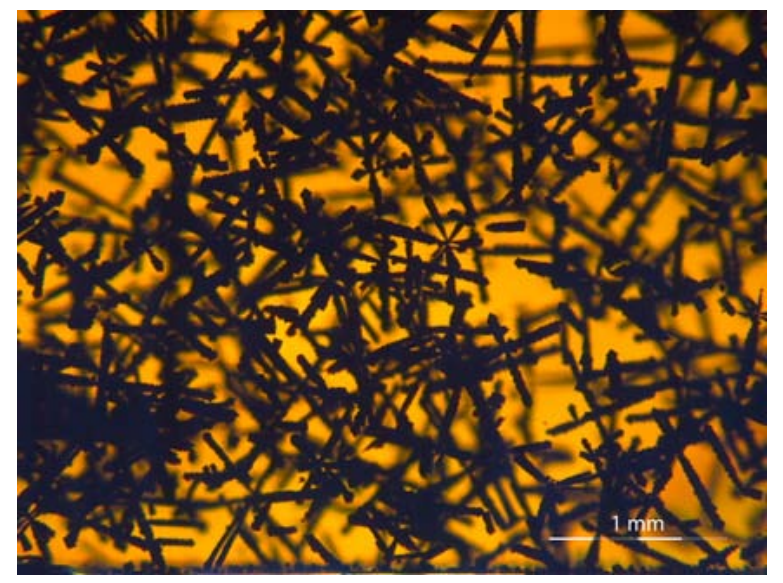

B

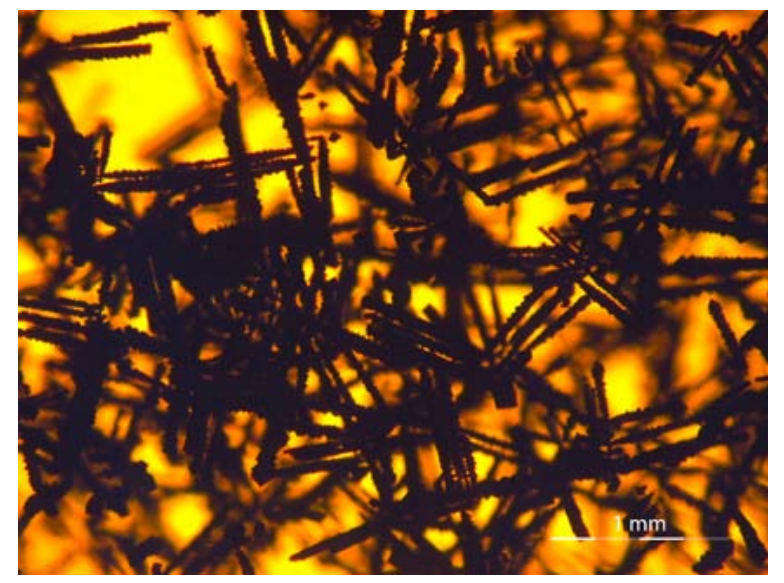

Figure 6. Transmitted-Light Optical Microscope Images of Spinel Crystals in Selected Glasses HeatTreated at $850^{\circ} \mathrm{C}$ for $\sim 7$ Days: A) Ni1.5/Al10 (6 days 23 hours 40 minutes) and B) Ni1.5/Li3.8 (7 days 1 hour)

A

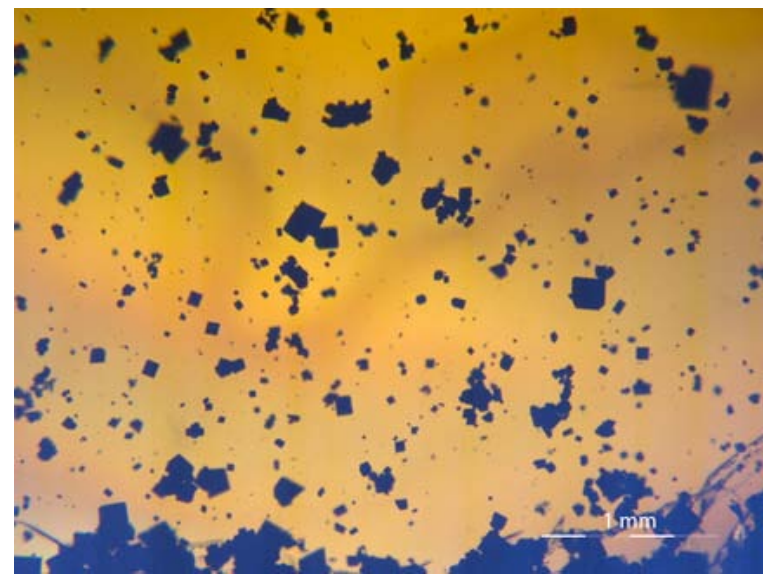

C

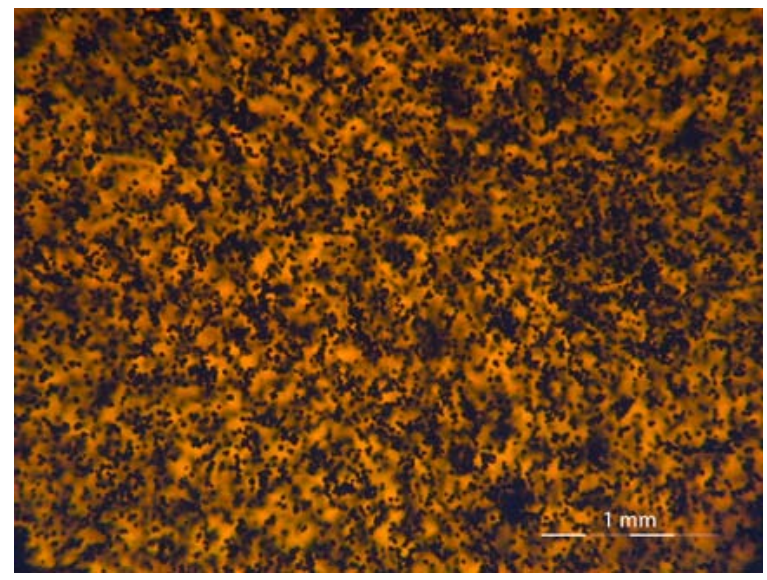

B

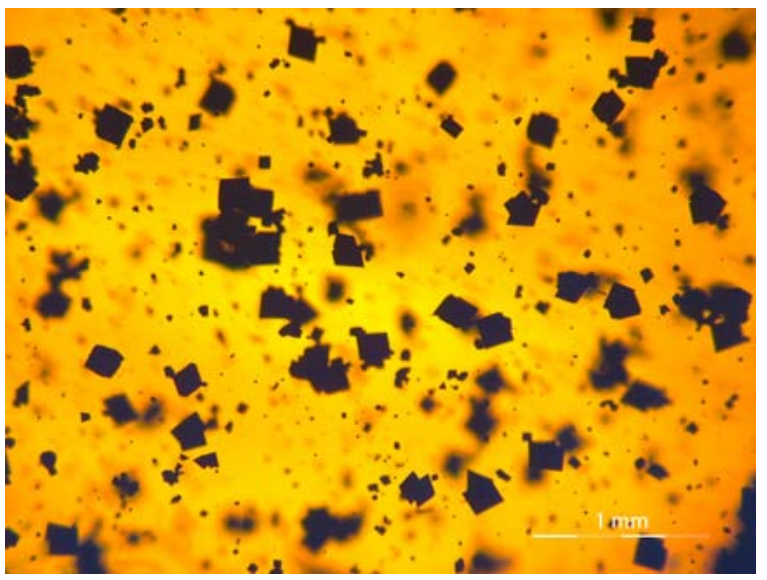

$\mathrm{D}$

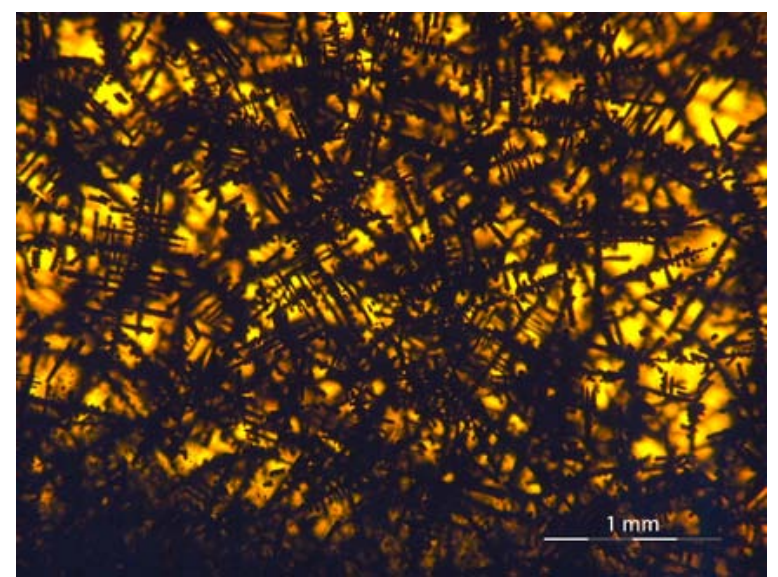

Figure 7. Transmitted-Light Optical Microscope Images of Spinel Crystals in Previously Tested Glasses (Matyáš et al. 2010a, 2010b) Heat-Treated at $850^{\circ} \mathrm{C}$ for Different Times: A) Ni1.07 (6 days 21 hours), B) Ni1.5 (7 days), C) Ni1.5/nm (7 days 20 minutes), and D) Ni1.5/Fe20 (9 days 19 hours 20 minutes) 


\subsection{Accumulation of Spinel Crystals}

Figure 8 shows the accumulation rates for spinel layer in the glasses that were heat-treated in double crucibles at $850^{\circ} \mathrm{C}$ for various times. The results for previously tested baseline (BL) and high-nickel (Ni1.5) glasses (Matyáš et al. 2010a, 2010b) were added to the plot for comparison purposes. The baseline glass contained 0.64 mass $\%$ of $\mathrm{NiO}, 0.17$ mass $\%$ of $\mathrm{Cr}_{2} \mathrm{O}_{3}$, and 14.51 mass $\%$ of $\mathrm{Fe}_{2} \mathrm{O}_{3}$ while Ni1.5 glass contained 1.5 mass\% of $\mathrm{NiO}, 0.17$ mass $\%$ of $\mathrm{Cr}_{2} \mathrm{O}_{3}$, and 14.38 mass $\%$ of $\mathrm{Fe}_{2} \mathrm{O}_{3}$. Table 8 shows the slopes and intercepts for linear fitted lines in the Figure 8.

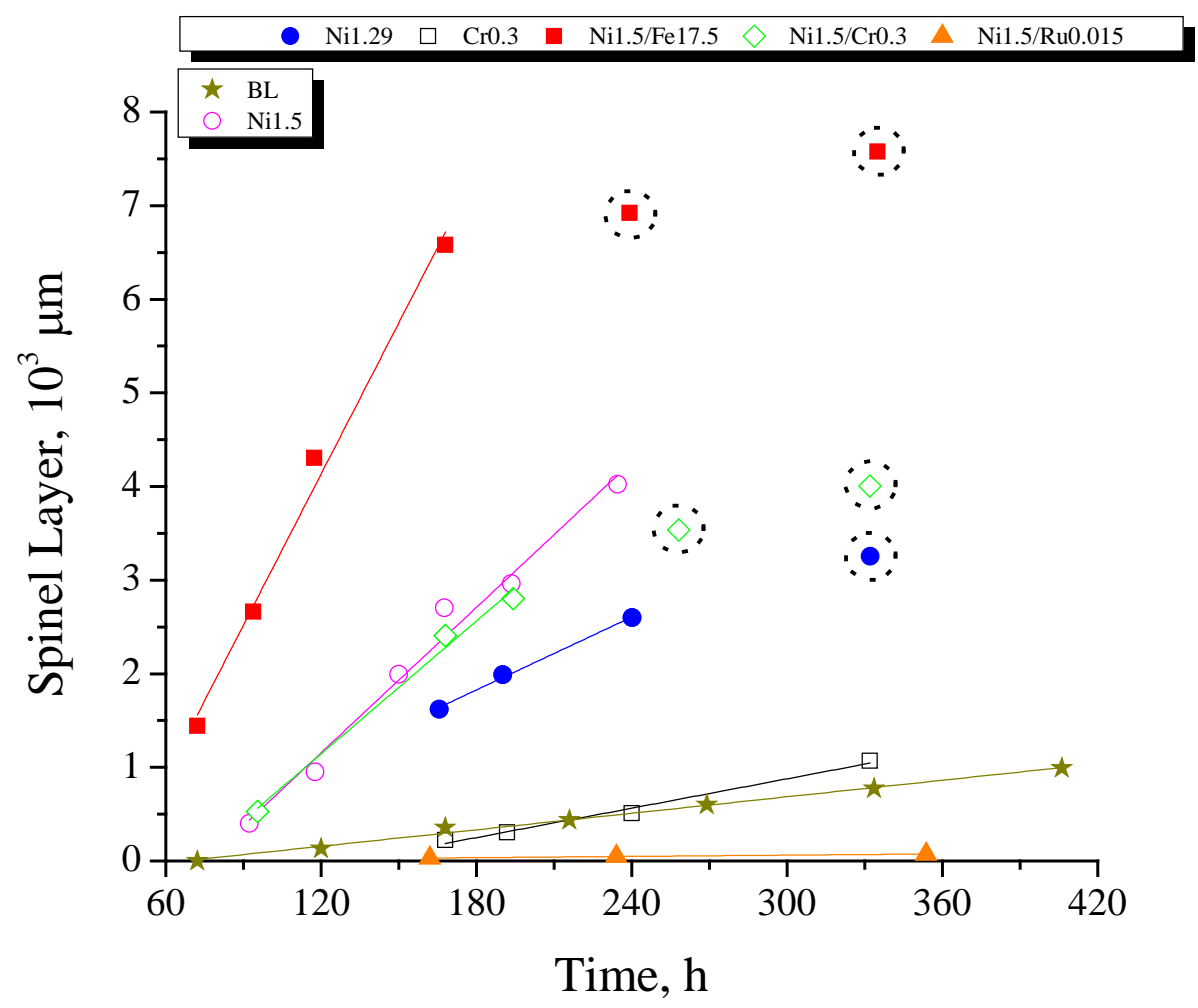

Figure 8. Thickness of Deposited Spinel Sludge Layer as a Function of Time. The lines were fitted with linear equation $\mathrm{y}=\mathrm{Ax}+\mathrm{B}$. The circled points represent the post-settling period (last paragraph on page 16).

Table 8. Slope (A) and Intercept (B) for Linear Fitted Lines in Figure 8

\begin{tabular}{lrrc}
\hline \multicolumn{1}{c}{ Glass ID } & $\mathrm{A}, \mu \mathrm{m} / \mathrm{h}$ & $\mathrm{B}, \mu \mathrm{m}$ & $R^{2}$ \\
\hline $\mathrm{BL}^{(\mathrm{a})}$ & 2.940 & -196.01 & 0.99 \\
$\mathrm{Ni1} .5^{(\mathrm{a})}$ & 25.892 & -1951.36 & 0.98 \\
$\mathrm{Ni1} .29$ & 12.970 & -507.39 & 1 \\
$\mathrm{Cr} 0.3$ & 5.231 & -691.66 & 0.99 \\
$\mathrm{Ni1} .5 / \mathrm{Fe} 17.5$ & 53.793 & -2321.20 & 0.99 \\
Ni1.5/Cr0.3 & 23.643 & -1691.97 & 0.99 \\
Ni1.5/Ru0.015 & 0.224 & -4.69 & 0.99 \\
\hline
\end{tabular}

(a) Previously tested glasses (Matyáš et al. 2010a, 2010b). 
Adding 0.13 mass $\%$ of $\mathrm{Cr}_{2} \mathrm{O}_{3}$ to the baseline increased the accumulation rate of spinel from $\sim 2.9$ to $5.2 \mu \mathrm{m} / \mathrm{h}$. Doubling the concentration of $\mathrm{NiO}$ in the baseline to 1.29 mass\% (Ni1.29 glass) increased the accumulation rate $\sim 4.5$ times to $\sim 13 \mu \mathrm{m} / \mathrm{h}$. An additional increase of $\mathrm{NiO}$ concentration to $1.5 \mathrm{mass} \%$ (Ni1.5 glass) resulted in the accumulation rate $\sim 25.9 \mu \mathrm{m} / \mathrm{h}$, approximately 9 times faster than that of the baseline. This rate was more than doubled to $\sim 53.8 \mu \mathrm{m} / \mathrm{h}$ by adding $\sim 3$ mass $\%$ of $\mathrm{Fe}_{2} \mathrm{O}_{3}$ to Ni1.5 glass (Ni1.5/Fe17.5 glass). In contrast, adding 0.13 mass $\%$ of $\mathrm{Cr}_{2} \mathrm{O}_{3}$ or 0.015 mass $\%$ of $\mathrm{RuO}_{2}$ to Ni1.5 glass (Ni1.5/Cr0.3 or Ni1.5/Ru0.015 glass) decreased this rate to $\sim 23.6$ or $0.2 \mu \mathrm{m} / \mathrm{h}$, respectively. More than twofold decrease in the accumulation rate for the Ni1.5/Ru0.015 glass demonstrates the high effectiveness of $\mathrm{RuO}_{2}$ in slowing down the spinel accumulation. This was confirmed by adding 0.087 mass $\%$ of $\mathrm{RuO}_{2}$ to Ni1.5 glass (Ni1.5/Ru0.087), which completely stopped the spinel accumulation.

Figure 9 shows the time-sequence SEM images of Ni1.5/Fe17.5 glass after heat-treatments at $850^{\circ} \mathrm{C}$, visualizing the growth of spinel sludge layer over the time as well as the size and concentration of crystals. Figure 10 provides a 3D projection of spinel agglomerates in the Ni1.5/Fe17.5 glass after heattreatment at $850^{\circ} \mathrm{C}$ for 4 days 21 hours $20 \mathrm{~min}$. Cyan-colored features of agglomerates are located on the surface and black-colored features in the bulk of the glass. Platelets of hematite that were identified in this glass encouraged the formation of large agglomerates bigger than $500 \mu \mathrm{m}$.

Figure 11 shows accumulated layers in the Ni1.5/Ru0.015, Cr0.3, Ni1.29, and Ni1.5/Cr0.3 glasses that were heat-treated at $850^{\circ} \mathrm{C}$ for $\sim 7$ days. The crystals up to $25 \mu \mathrm{m}$ in size were found in the Ni1.5/Ru0.015 glass with $\sim 25 \%$ of all the crystals bigger than $10 \mu \mathrm{m}$. The average crystal size was 8.4 $\pm 9.9 \mu \mathrm{m}$. In contrast, all the crystals in the Cr0.3 glass were bigger than $14 \mu \mathrm{m}$. Also, the average and maximum size of crystals was $49.4 \pm 50.3$ and $110 \mu \mathrm{m}$, respectively. Crystals formed in the Ni1.29 glass were more than double of that size, $116.1 \pm 120.9$ and $294 \mu \mathrm{m}$, due to agglomeration (see Figure 4C) and fast crystal growth. Also, about half of the crystals in the layer were bigger than $100 \mu \mathrm{m}$. Similar large single crystals and agglomerates were observed in the Ni1.5/Cr0.3 glass (see Figure 4B) but their average and maximum size was $127.4 \pm 139.9$ and $354 \mu \mathrm{m}$, respectively.

Figure 12 shows SEM images of crystals on the surface of the thin-sections for the Ni15/Al10 and $\mathrm{Ni1} .5 / \mathrm{Li} 3$ glasses that were heat-treated at $850^{\circ} \mathrm{C}$ for $\sim 7$ days. Crystals in these glasses did not form a compacted settling layer because of an extensive network of interconnected large needle-like spinel structures. The area fraction of the crystals in the layers did not change with time and was less than $8 \%$. Figure 13 details the size of spinel in the crystal clouds observed in the Ni1.5/Ru0.087 glass after 7 days of heat-treatment at $850^{\circ} \mathrm{C}$. An average crystal size varied from $3 \pm 2.6 \mu \mathrm{m}$ (Figure 13A) to $4.9 \pm 4.9 \mu \mathrm{m}$ (Figure 13B) and the maximum size of crystals was $\sim 10 \mu \mathrm{m}$.

Points marked by dot circles in Figure 8 represent a post-settling period in Ni1.29, Ni1.5/Cr0.3, and Ni1.5/Fe17.5 glasses. In this period, the accumulation rate of spinel crystals was slower than in the linear-settling period because fewer and smaller crystals were available for settling. This is illustrated by the Figure 14, which shows the layer of spinel accumulated in Ni1.5/Cr0.3 glass after 13 days and 20 hours at $850^{\circ} \mathrm{C}$. The highlighted area at the top contains crystals with an average size $99 \mu \mathrm{m}$. In contrast, the average size of the crystals settled during linear-settling period (middle section of Figure 9) was $\sim 139 \mu \mathrm{m}$. The pre-settling period is represented by highlighted area at the bottom of Figure 14. In this period, crystals with an average size $\sim 55 \mu \mathrm{m}$ got accumulated in the layer. Their small size compared to crystals at the top and middle sections can be explained by settling of crystals formed close to the bottom. These crystals grew slowly or stopped growing because the glass in their vicinity was depleted from spinel constituents. 
A

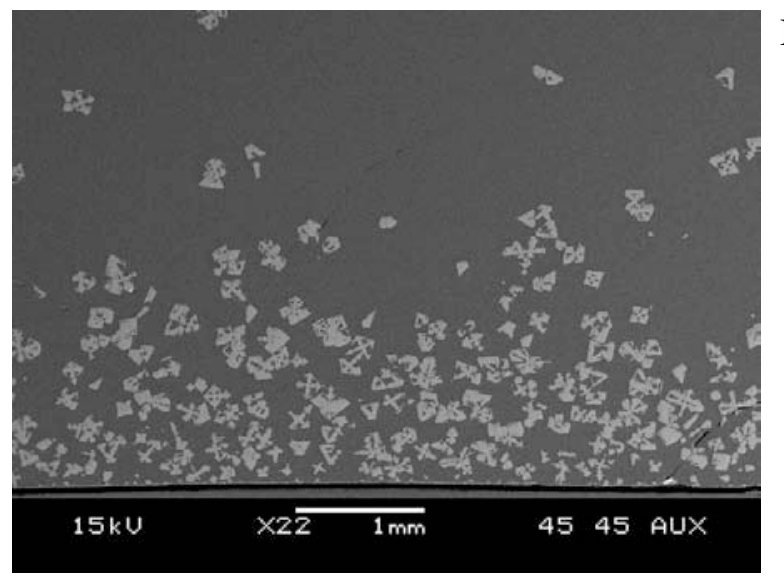

C

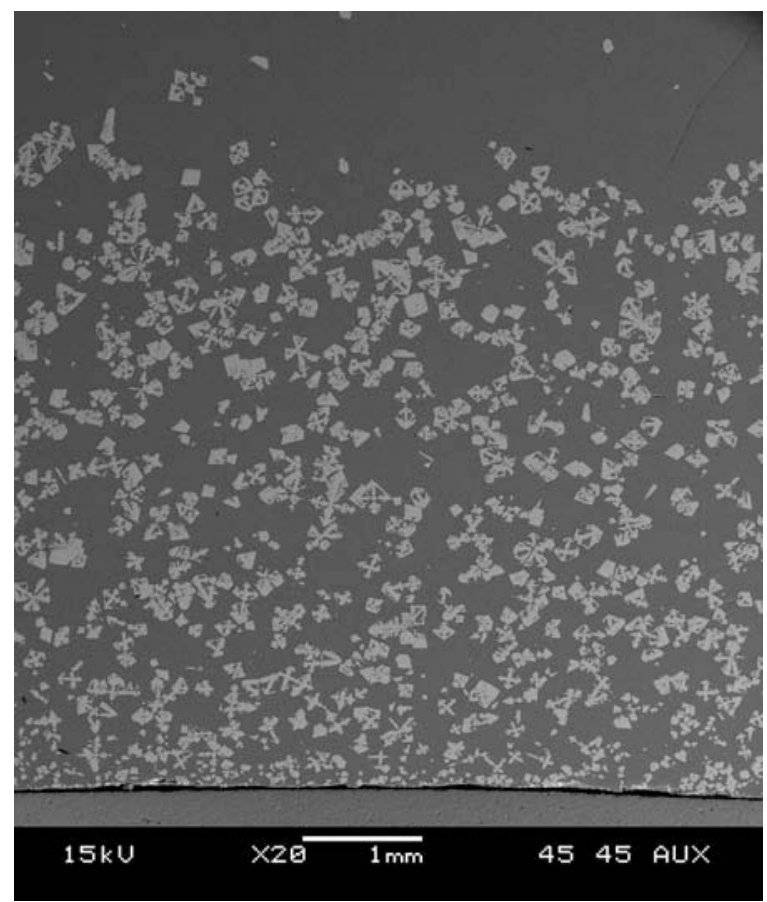

B

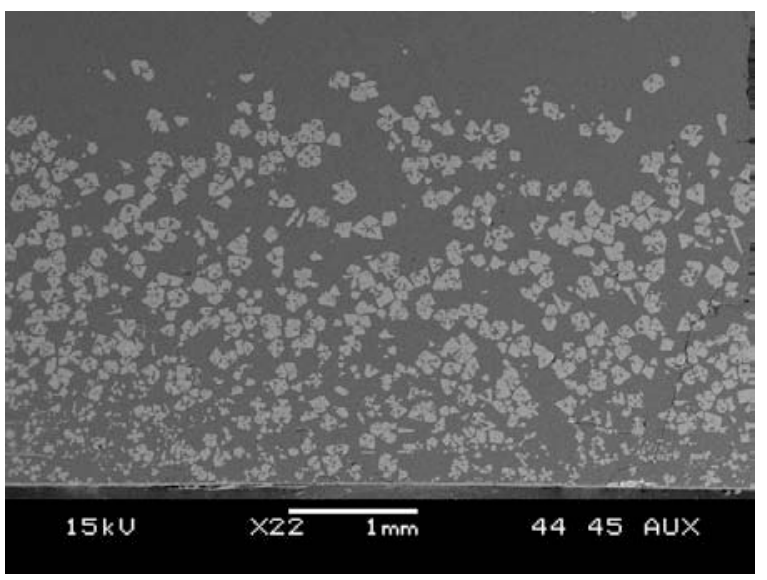

$\mathrm{D}$

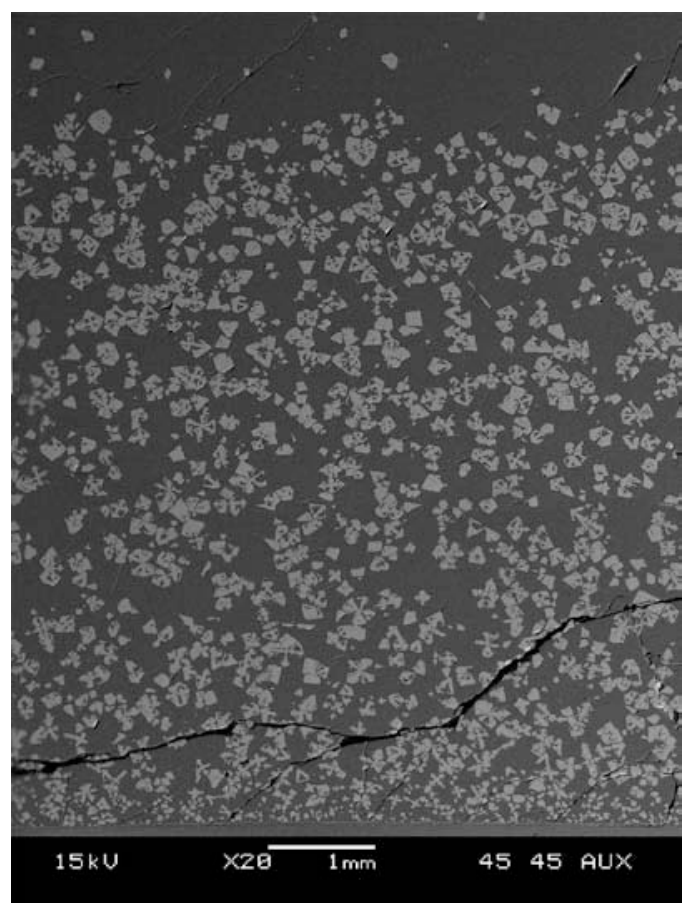

Figure 9. SEM Images of Accumulated Spinel Layer in the Ni1.5/Fe17.5 Glass After Heat-Treatment at $850^{\circ} \mathrm{C}$ for A) 3 Days 10 Minutes $\left.(1440.4 \mu \mathrm{m}), \mathrm{B}\right) 3$ Days 21 Hours 45 Minutes (2662.1 $\left.\mu \mathrm{m}\right)$, C) 4 Days 21 Hours 20 Minutes $(4305.9 \mu \mathrm{m})$, and D) 7 Days $(6580.8 \mu \mathrm{m})$ 


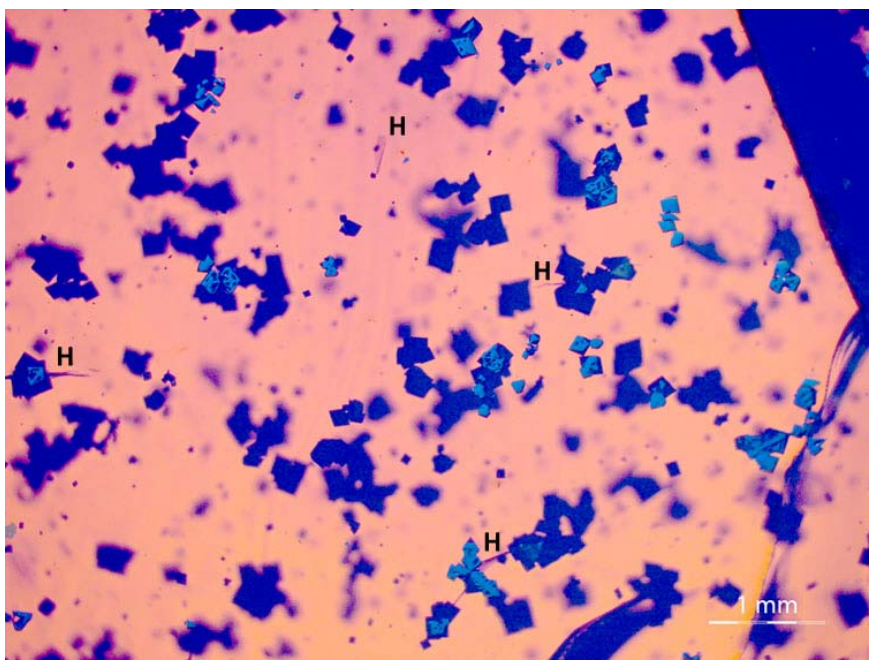

Figure 10. Transmitted-Light Optical Microscope Images of Spinel Crystals and Hematite (H: platelets in the bulk of the glass) in Ni1.5/Fe17.5 Glass Heat-Treated at $850^{\circ} \mathrm{C}$ for 4 Days 21 Hours 20 Minutes (cyan-colored features of agglomerates are on the surface and black-colored features in the bulk of the glass)

A

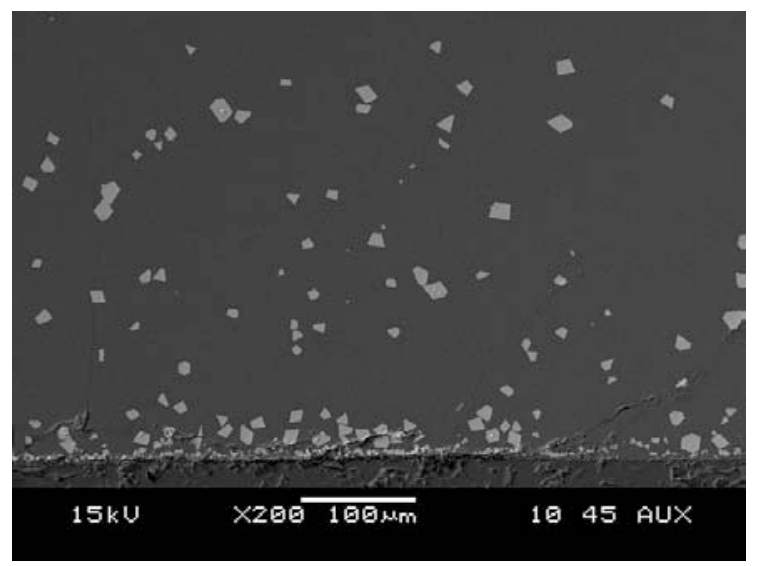

$\mathrm{C}$

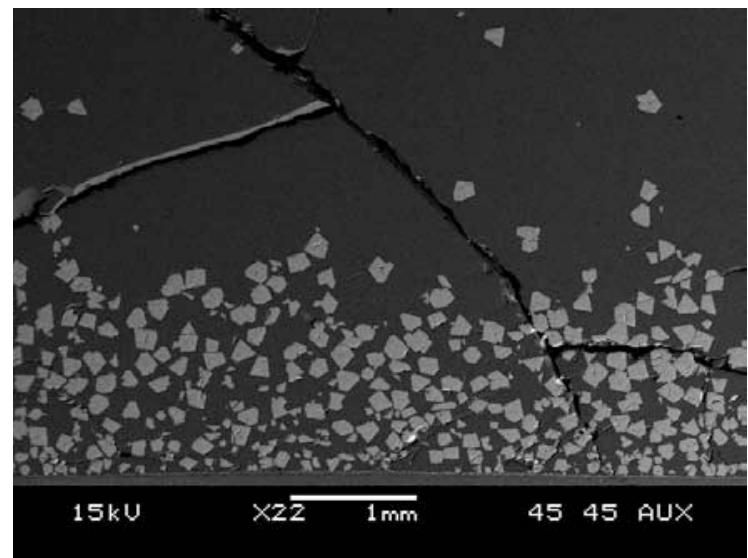

B

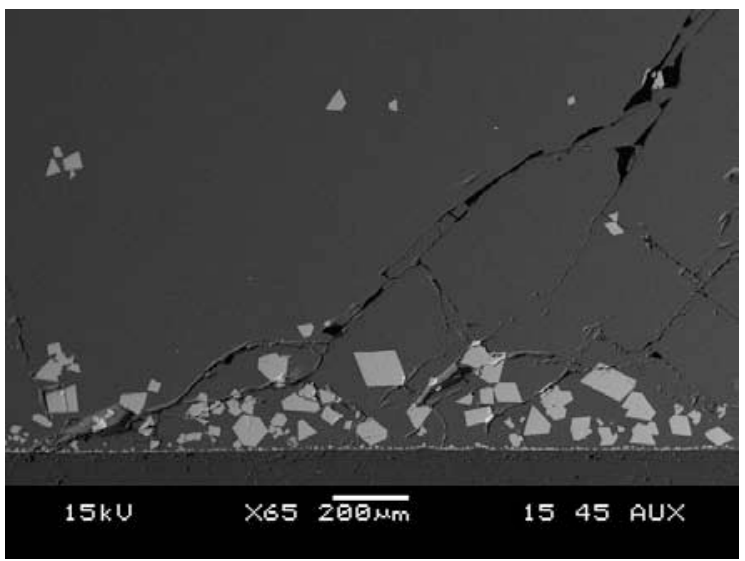

$\mathrm{D}$

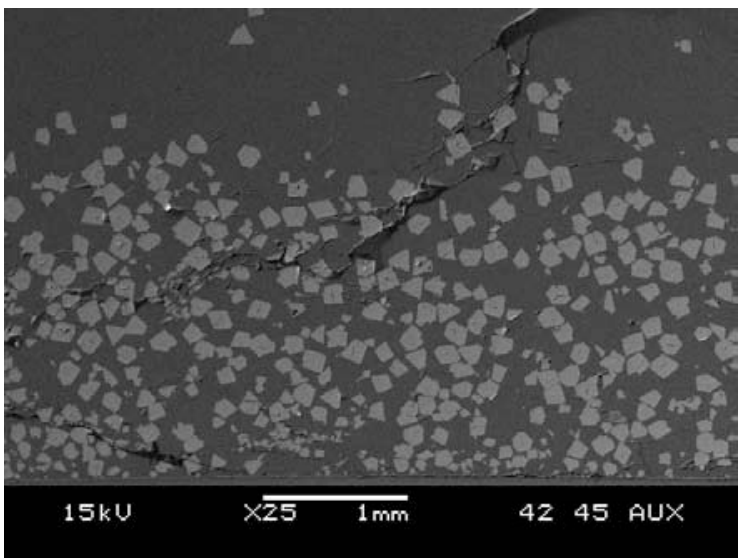

Figure 11. SEM Images of Spinel Layers Deposited at $850^{\circ} \mathrm{C}$ : A) Ni1.5/Ru0.015 -6 days 19 hours 5 minutes $(29.9 \mu \mathrm{m}), \mathrm{B}) \mathrm{Cr} 0.3-7$ days $(222.4 \mu \mathrm{m}), \mathrm{C})$ Ni1.29 - 6 days 21 hours 35 minutes $(1621 \mu \mathrm{m})$, and D) Ni1.5/Cr0.3 - 7 days $(2409.1 \mu \mathrm{m})$ 
A

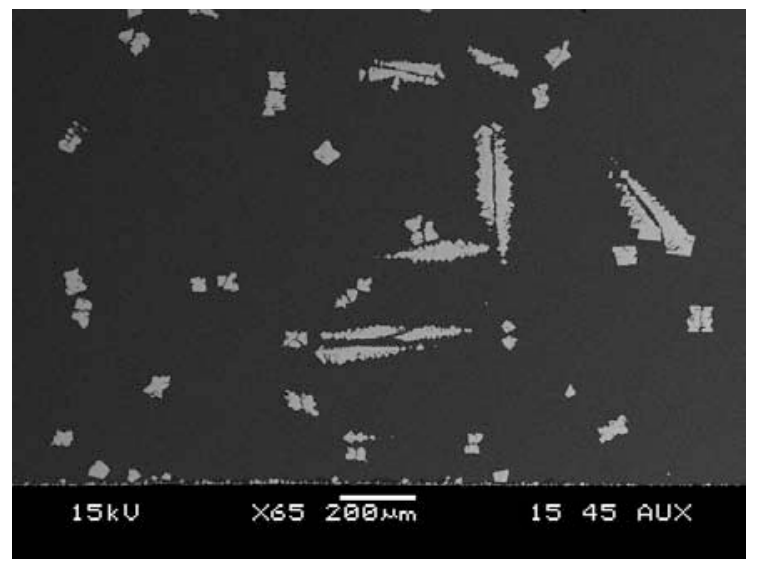

B

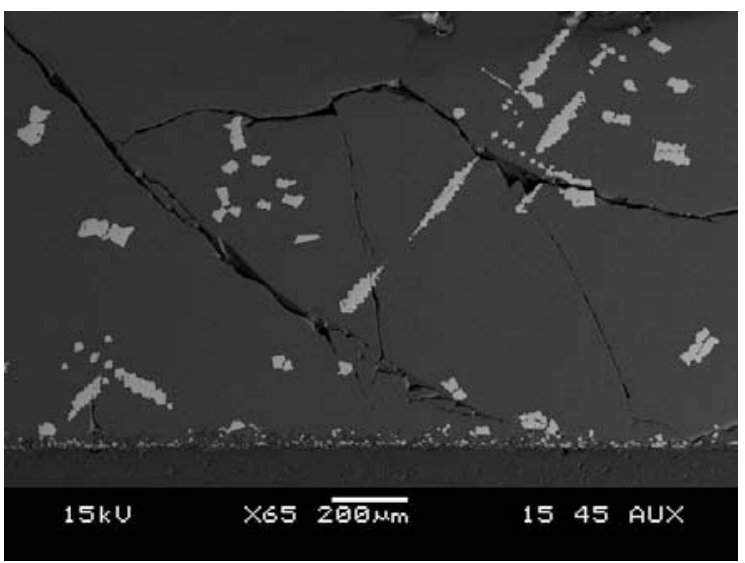

Figure 12. SEM Images of Crystals on the Surface of the Thin-Sections for Glasses Heat-Treated at $850^{\circ} \mathrm{C}$ for $\sim 7$ Days: A) Ni15/Al10 - 6 days 23 hours 40 minutes and B) Ni1.5/Li3.8 - 7 days 1 hour

A

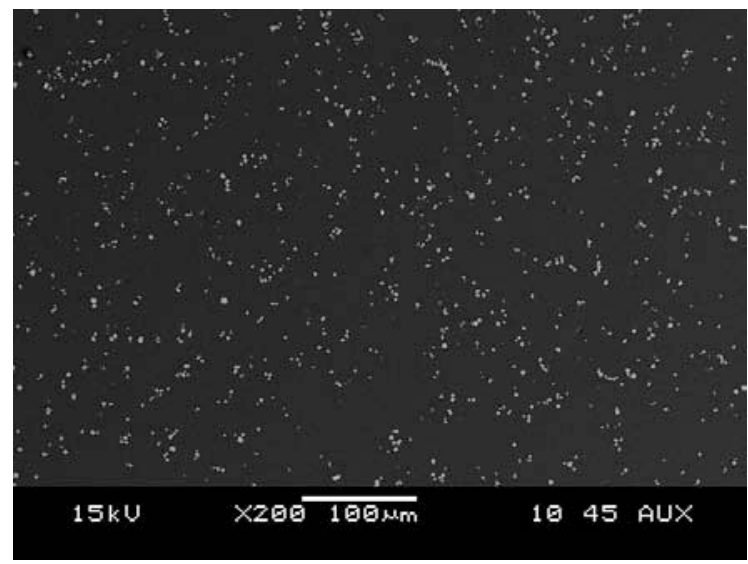

B

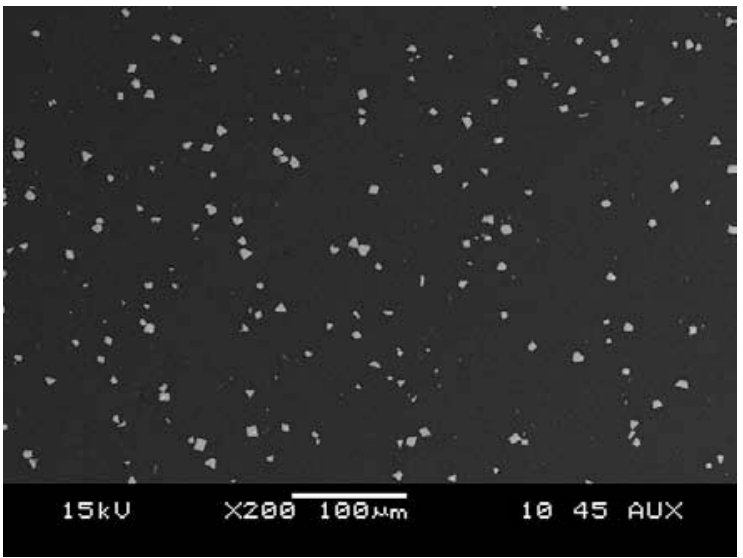

Figure 13. SEM Images of Crystal Clouds Found in the Ni1.5Ru0.087 Glass After 7 Days of HeatTreatment at $850^{\circ} \mathrm{C}$. An average size of crystals A) $\left.3 \pm 2.6 \mu \mathrm{m}, \mathrm{B}\right) 4.9 \pm 4.9 \mu \mathrm{m}$.

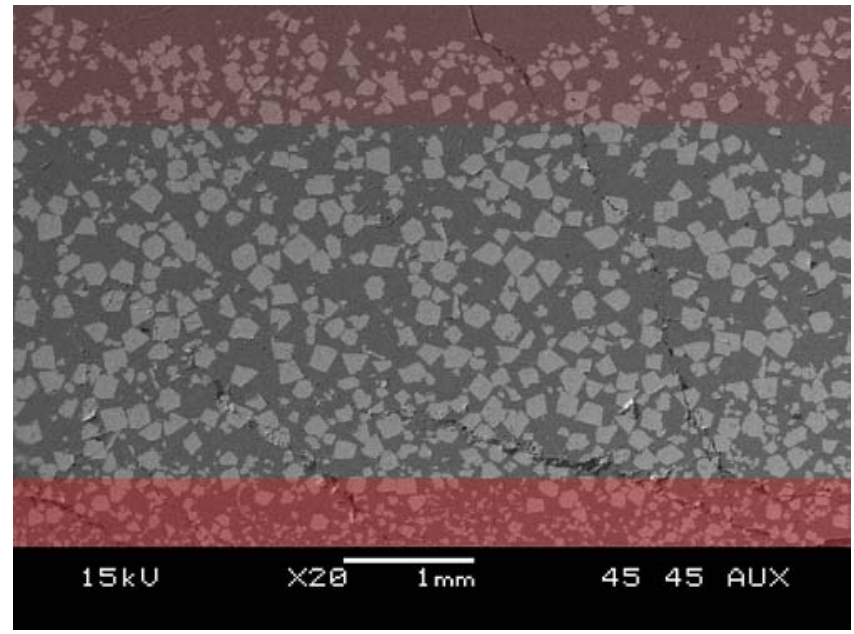

Figure 14. SEM Image of Accumulated Spinel Layer in the Ni1.5/Cr0.3 Glass After Heat-Treatment at $850^{\circ} \mathrm{C}$ for 13 Days and 20 Hours. Top and bottom highlighted areas represent post-settling and pre-settling period, respectively. 


\subsection{Crystal-Tolerant Glass Model}

Previously, we have developed an empirical model of spinel settling with coefficients $h_{i}$ and $s_{i}$ expressed as a linear function of mass fractions of seven major components $\left(\mathrm{Al}_{2} \mathrm{O}_{3}, \mathrm{Cr}_{2} \mathrm{O}_{3}, \mathrm{Fe}_{2} \mathrm{O}_{3}\right.$, $\mathrm{ZnO}$, $\mathrm{MnO}, \mathrm{NiO}$, and Others) to predict crystal accumulation in the glass discharge riser of the HLW melter (Matyáš et al. 2010a):

$$
h=\sum_{i=1}^{7} h_{i} x_{i}+t \sum_{i=1}^{7} s_{i} x_{i}
$$

where $h_{i}$ is a compositional dependent intercept coefficient $(\mu \mathrm{m}), t$ is the settling time $(\mathrm{h})$, and $s_{i}$ is a compositional dependent velocity coefficient $(\mu \mathrm{m} / \mathrm{h})$.

In this study, additional spinel-layer-thickness data were generated and incorporated into this model. Specifically, the experimental data were updated with thicknesses of accumulated layers observed in Ni1.5/Cr0.3, Cr0.3 and Ni1.29 glasses. Table 9 shows the calculated coefficients $h_{i}$ and $s_{i}$, the values of $\mathrm{R}^{2}$ (expresses the fraction of the variability accounted for by the model), and $R_{a d j}^{2}$ (adjusts $\mathrm{R}^{2}$ for the number of parameters used in fitting the model). The positive coefficients $s_{i}$ for $\mathrm{MnO}, \mathrm{ZnO}, \mathrm{Cr}_{2} \mathrm{O}_{3}$, and $\mathrm{NiO}$ indicates that these components increase the rate of accumulation. In contrast, additions of $\mathrm{Al}_{2} \mathrm{O}_{3}$ and $\mathrm{Fe}_{2} \mathrm{O}_{3}$ decrease the accumulation rate. Also, our experiments showed that the detrimental effect of the most troublesome component $(\mathrm{NiO})$ on the accumulation rate can be significantly suppressed by adding $\mathrm{RuO}_{2}$ to the glass.

Table 9. Component Coefficients Calculated with an Empirical Model (Matyáš et al. 2010a)

\begin{tabular}{lrr}
\hline Components & \multicolumn{1}{c}{$h_{i}(\mu \mathrm{m})$} & $s_{i}(\mu \mathrm{m} / \mathrm{h})$ \\
\hline $\mathrm{Al}_{2} \mathrm{O}_{3}$ & 9206 & -339 \\
$\mathrm{Fe}_{2} \mathrm{O}_{3}$ & 4895 & -52 \\
$\mathrm{MnO}$ & 7734 & 189 \\
$\mathrm{ZnO}$ & -15287 & 342 \\
$\mathrm{Cr}_{2} \mathrm{O}_{3}$ & -62253 & 520 \\
$\mathrm{NiO}$ & -176907 & 2498 \\
Others & -768 & 28 \\
$\mathrm{R}^{2}$ & & 0.981 \\
$\mathrm{R}^{2}$ adj & & \\
\hline
\end{tabular}

Figure 15 shows the calculated versus measured thicknesses of a spinel sludge layer for the glasses used in the model fit and for Ni1.5/Fe17.5 glass. The model predicts well the accumulation of crystals in the glasses with no or small-scale agglomeration, in which spinel settles as individual crystals and/or as clusters of a few crystals. Fitting 44 data points resulted in $\mathrm{R}^{2}=0.981$. But, in the case of excessive agglomeration, observed in the Ni1.5/Fe17.5 glass, the model under predicts the thicknesses of deposited layers. This under prediction was getting gradually worse with time as an increased number of larger agglomerates formed. Another factor that affected greatly the accumulation of spinel was the formation of 3D network of spinel needles in the Ni1.5/Al10 and Ni1.5/Li.38 glasses, which prevented a 
development of a dense settled layer. Since dense layers did not form in these glasses, they were excluded from model fitting. An addition, we were not able to detect continuous accumulated layers of spinel for Ni1.5/Ru0.015 glass, and therefore, did not use this glass in the model fitting as well.

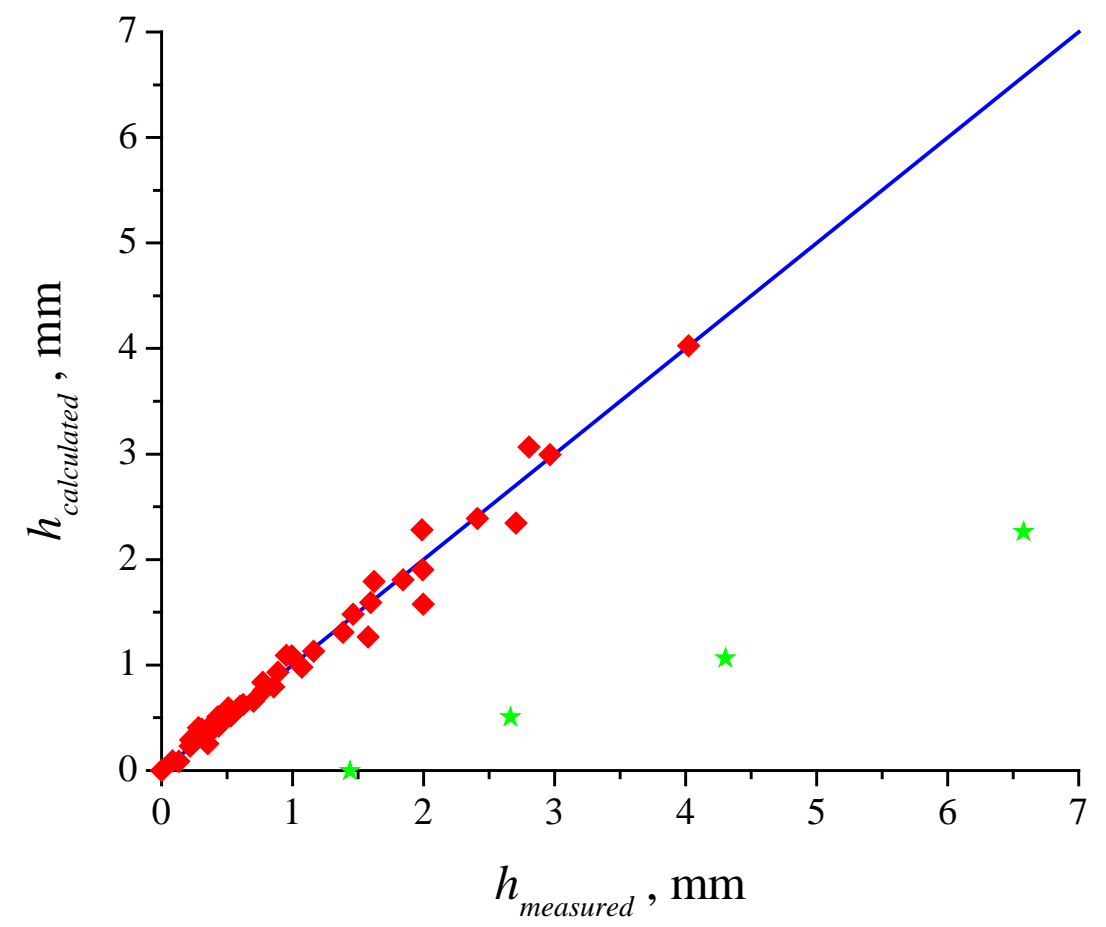

Figure 15. Calculated vs. Measured Thicknesses of Accumulated Layers for the Glasses Used in the Model Fit (red diamonds) and for Ni1.5/Fe17.5 Glass (green stars)

\subsection{Particle Agglomeration}

A question arises whether it would be possible to control the accumulation rate of spinel crystals through optimization of noble metals concentration in radioactive wastes. A small concentration of noble metals may be sufficient to nucleate enough spinel crystals to limit their growth to a size of $10 \mu \mathrm{m}$ or less. However, high concentrations of noble metals are not favorable because of their tendency to form large agglomerates (Fox et al. 2008). These rapidly settling agglomerates can also form due to interactions of spinel crystals with noble metal particles. Therefore, our laboratory study investigated particle agglomeration (size and concentration of agglomerates) and accumulation rates in two designed HLW glass compositions with X-ray tomography, optical microscopy, and SEM-EDS.

Figure 16 shows the testing assembly that was used in the lab-scale study of the particle agglomeration. The assembly consisted of an alumina crucible with an outer and inner diameter of 1.8 and $1.5 \mathrm{~cm}$, respectively, and height $9 \mathrm{~cm}$ that was positioned on the alumina plate inside a Pt-crucible with a diameter of $3 \mathrm{~cm}$ and height $10 \mathrm{~cm}$. The fabricated glasses were first melted in $\mathrm{Pt} / 10 \% \mathrm{Rh}$ crucibles at $1200^{\circ} \mathrm{C}$ for an hour, and then the crucibles were removed one by one from the melting furnace, and molten glass poured into each of four assemblies that were rested on the 20-in.-diameter platform inside the big Deltech furnace at $850^{\circ} \mathrm{C}$. These assemblies were covered with a lid and removed (air-quenched) at different times up to 4 days. The alumina crucibles were core-drilled from assemblies 
and were investigated with X-ray tomography for the size and distribution of agglomerates. Then, the thin sections were prepared for optical microscopy and SEM-EDS observations, and an image analysis.

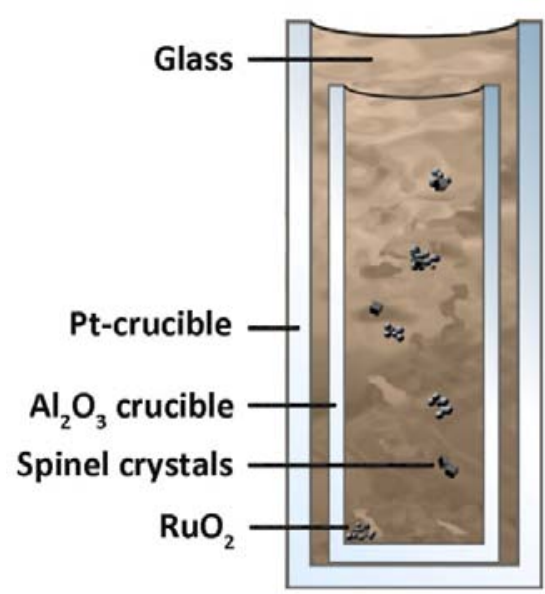

Figure 16. Cross-Section of Testing Assembly

\subsection{X-Ray Tomography}

The core-drilled alumina crucibles were analyzed with a resolution of $17.5 \mu \mathrm{m}$ (the smallest agglomerate that can be detected). The image analysis focused on the area $\sim 3 \times 1.5 \mathrm{~cm}$ inside the crucible at the bottom which was covered by $1714 \mathrm{XY}$ (top view) and $857 \mathrm{XZ}$ (side view) slices. Figure 17 shows agglomerates (white specs) in $\mathrm{XZ}$ slices collected in the middle of the crucible for $\mathrm{BL} / \mathrm{RuO}_{2}$ (A) and $\mathrm{Ni1} .5 / \mathrm{Ru}_{2}$ (B) glasses that were heat-treated at $850^{\circ} \mathrm{C}$ for $\sim 2$ days. The $\mathrm{BL} / \mathrm{RuO}_{2}$ contained 44 agglomerates of maximum and average sizes 412 and $111 \pm 159 \mu \mathrm{m}$, respectively. In contrast, $\mathrm{Ni1.5} / \mathrm{RuO}_{2}$ contained 41 agglomerates of maximum and average sizes 138 and $68 \pm 64 \mu \mathrm{m}$, respectively. These numbers suggest that significantly bigger agglomerates formed in the $\mathrm{BL} / \mathrm{RuO}_{2}$, but, this was not true as confirmed by image analysis of remaining XZ slices. The overall size distribution of agglomerates was not that markantly different. The averages of maximum and average sizes in the BL/RuO2 were $167 \pm 38$ and $94 \pm 12 \mu \mathrm{m}$, respectively, compared to $148 \pm 33$ and $86 \pm 9 \mu \mathrm{m}$ in the $\mathrm{Ni} 1.5 / \mathrm{RuO}_{2}$. Also, the numbers of agglomerates was about the same; $11 \pm 3$ and $10 \pm 3$ and agglomerates per $\mathrm{cm}^{2}$ in the $\mathrm{BL} / \mathrm{RuO}_{2}$ and $\mathrm{Ni1} .5 / \mathrm{RuO}_{2}$. In addition, we did not observe accumulated layer in any of these glasses even after 4 days at $850^{\circ} \mathrm{C}$, indicating that agglomerates of this size and shape configuration (see Figures 21 and 22) settle slowly.

Figure 18 shows agglomerates in XY slices collected at 1.6 (A) and $2.6 \mathrm{~cm}$ (B) above the bottom for $\mathrm{Ni1} .5 / \mathrm{Ru}_{2}$ glass heat-treated at $850^{\circ} \mathrm{C}$ for 1 day 21 hours and 15 minutes. About 17 agglomerates were detected closer to the bottom with the maximum and average sizes 153 and $95 \pm 73 \mu \mathrm{m}$, respectively. The higher number (27) and little bigger agglomerates were detected further from the bottom (maximum and average sizes 178 and $101 \pm 93 \mu \mathrm{m}$, respectively). Figure 19 and 20 shows maximum and average size of agglomerates as a function of the distance from the bottom of the crucible for $\mathrm{BL} / \mathrm{RuO}_{2}$ and $\mathrm{Ni1} .5 / \mathrm{RuO}_{2}$ glasses heat-treated at $850^{\circ} \mathrm{C}$ for $\sim 2$ days. The linear fit of the data indicates a gradual increase in the averages of maximum and average sizes of agglomerates from bottom to the top for tested glasses. This increase is similar in both glasses except for more than 3 times higher increase in maximum size for agglomerates in the $\mathrm{Ni1.5} / \mathrm{RuO}_{2}$. 
A

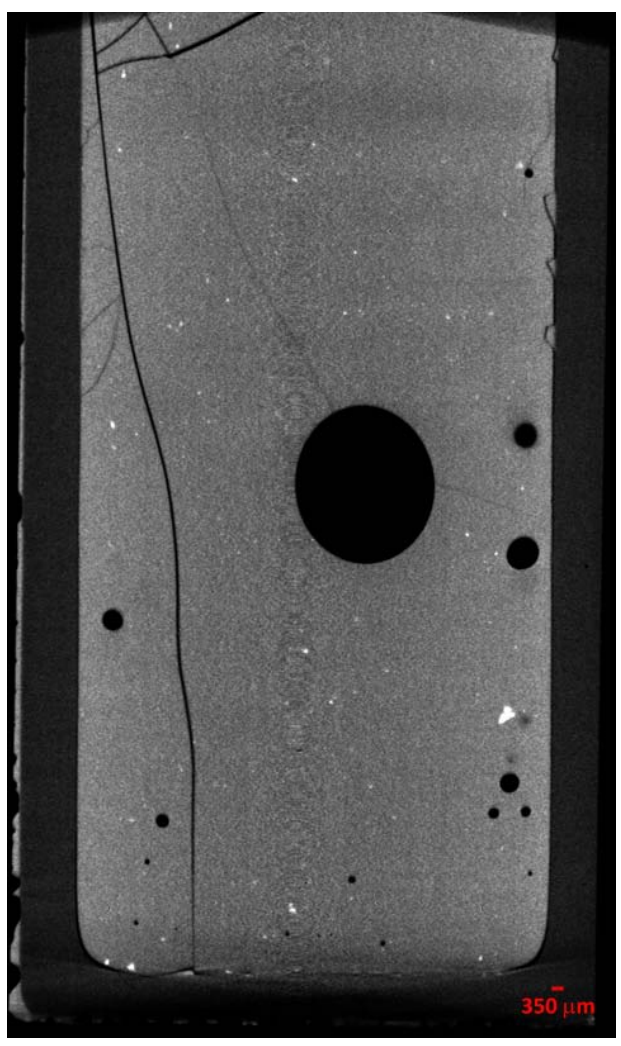

B

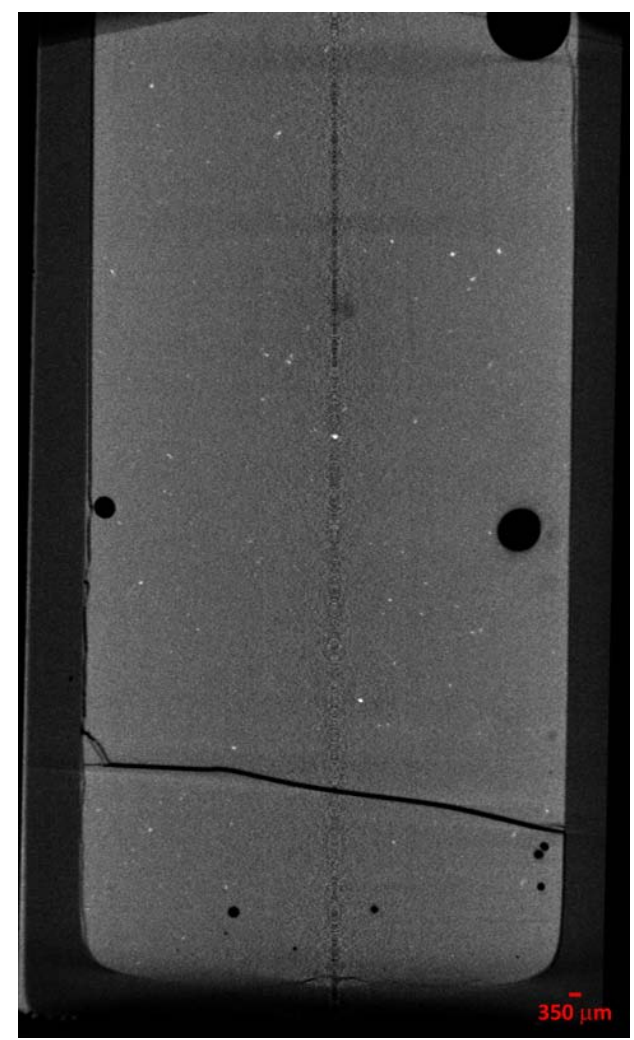

Figure 17. X-Ray Tomograph Images of Agglomerates (white specs) in the XZ Slice in the Middle of the Alumina Crucible (walls in dark gray) for $\mathrm{BL} / \mathrm{RuO}_{2}(\mathrm{~A})$ and $\mathrm{Ni1} .5 / \mathrm{RuO}_{2}$ (B) Glasses (gray areas) Heat-Treated at $850^{\circ} \mathrm{C}$ for 2 Days and 1 Day 21 Hours and 15 Minutes, Respectively (black rounded features are cavities and black lines are cracks)

A

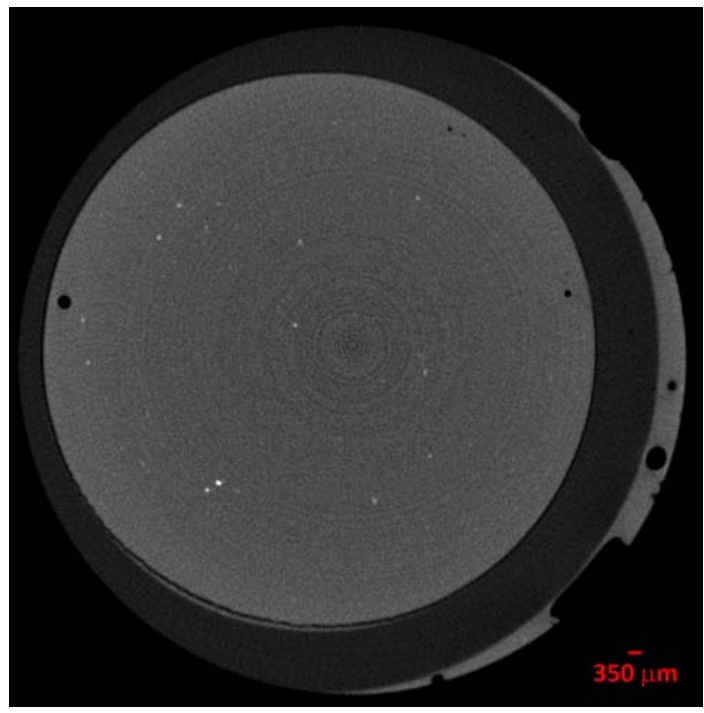

B

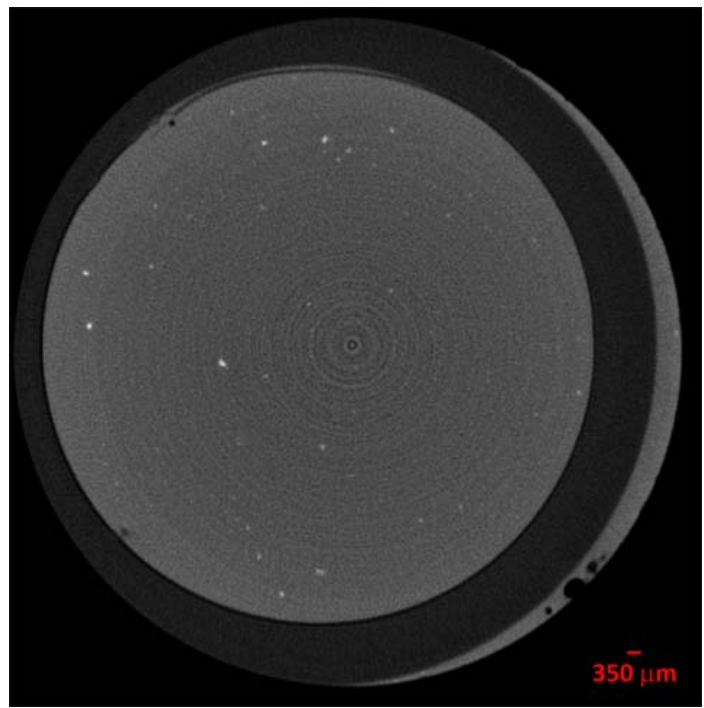

Figure 18. X-Ray Tomograph Images of Agglomerates (white specs) Formed in the Ni1.5/Ru0 $\mathrm{Glass}$ (gray areas) Heat-Treated in Alumina Crucible (dark gray circle) at $850^{\circ} \mathrm{C}$ for 1 Day 21 Hours and 15 Minutes: A) XY slice $1.6 \mathrm{~cm}$ above the bottom and B) XY slice $2.6 \mathrm{~cm}$ above the bottom 


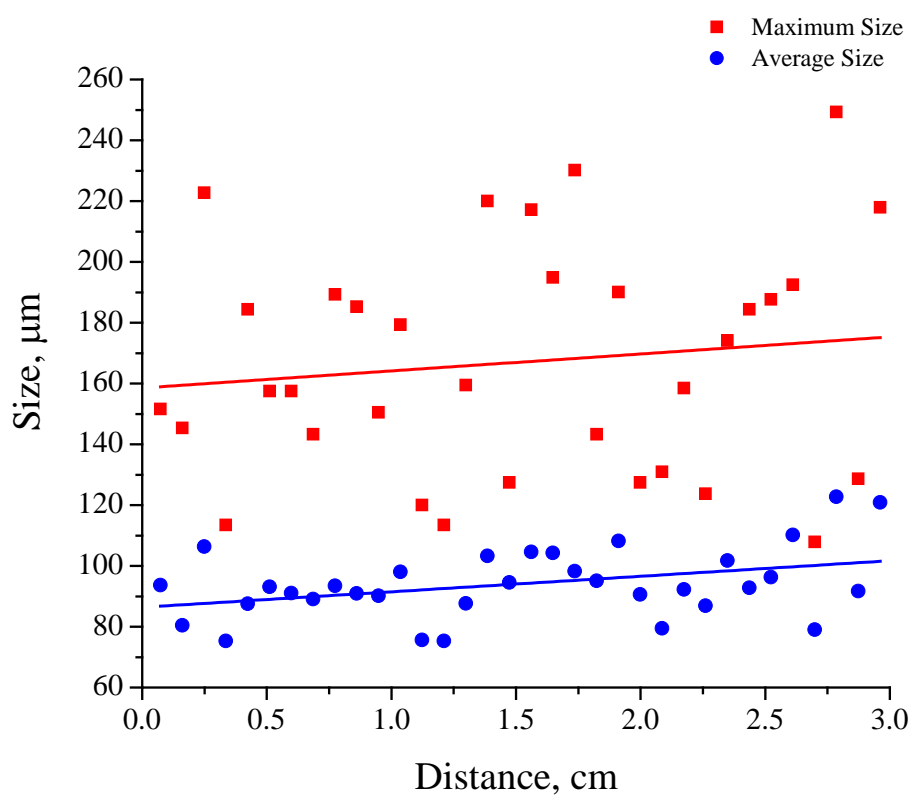

Figure 19. Maximum and Average Size of Agglomerates as a Function of the Distance from the Bottom of the Crucible; $\mathrm{BL} / \mathrm{RuO}_{2}$ Glass Heat-Treated at $850^{\circ} \mathrm{C}$ for 2 Days. The solid lines are linear fit of the data (maximum size: $y=5.6 x+158.5$ and average size: $y=5.1 x+86.4$ ).

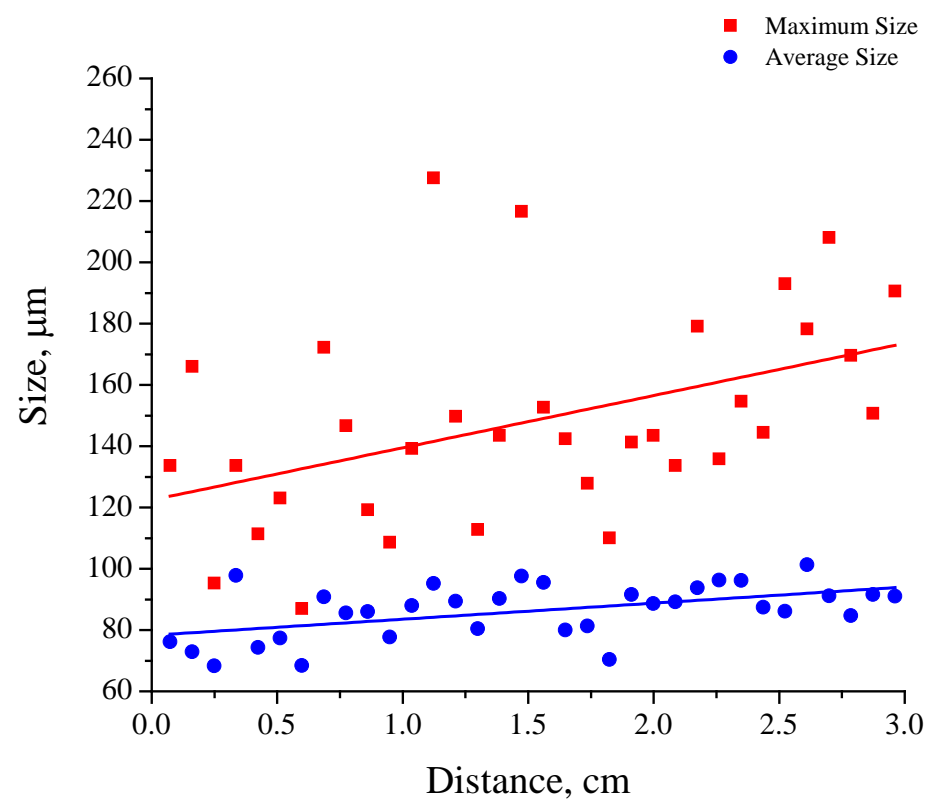

Figure 20. Maximum and Average Size of Agglomerates as a Function of the Distance from the Bottom of the Crucible; $\mathrm{Ni1.5} / \mathrm{RuO}_{2}$ Glass Heat-Treated at $850^{\circ} \mathrm{C}$ for 1 Day 21 Hours and 15 Minutes. The solid lines are linear fit of the data (maximum size: $y=17.1 x+122.4$ and average size: $y=5.3 x+78.3$ ). 


\subsection{SEM}

Figure 21 shows in detail the shape and size of the agglomerates that formed in the $\mathrm{Ni1} .5 / \mathrm{RuO}_{2}$ glass heat-treated at $850^{\circ} \mathrm{C}$ for A) 1 day 21 hours 15 minutes, B) 3 days 2 hours 45 minutes, and C) 4 days 5 minutes. Figure 22 shows the same for $\mathrm{BL} / \mathrm{RuO}_{2}$. SEM analysis proved that the size of agglomerates increases with time, and therefore, confirmed the results of X-ray tomography.

A

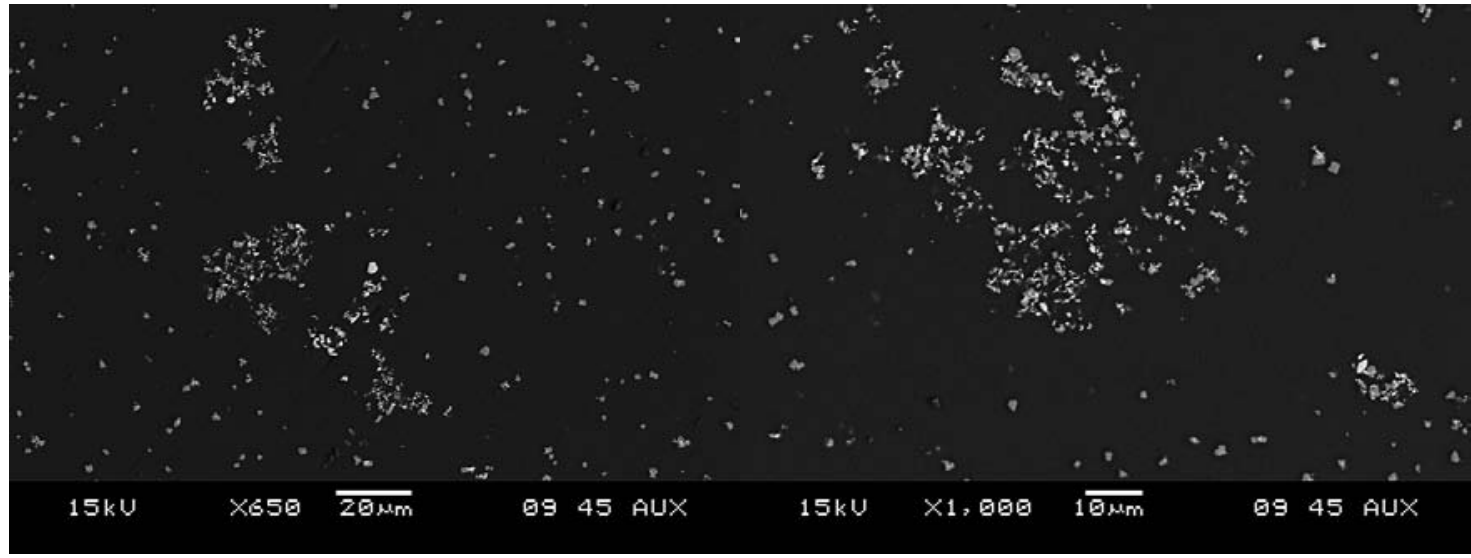

B

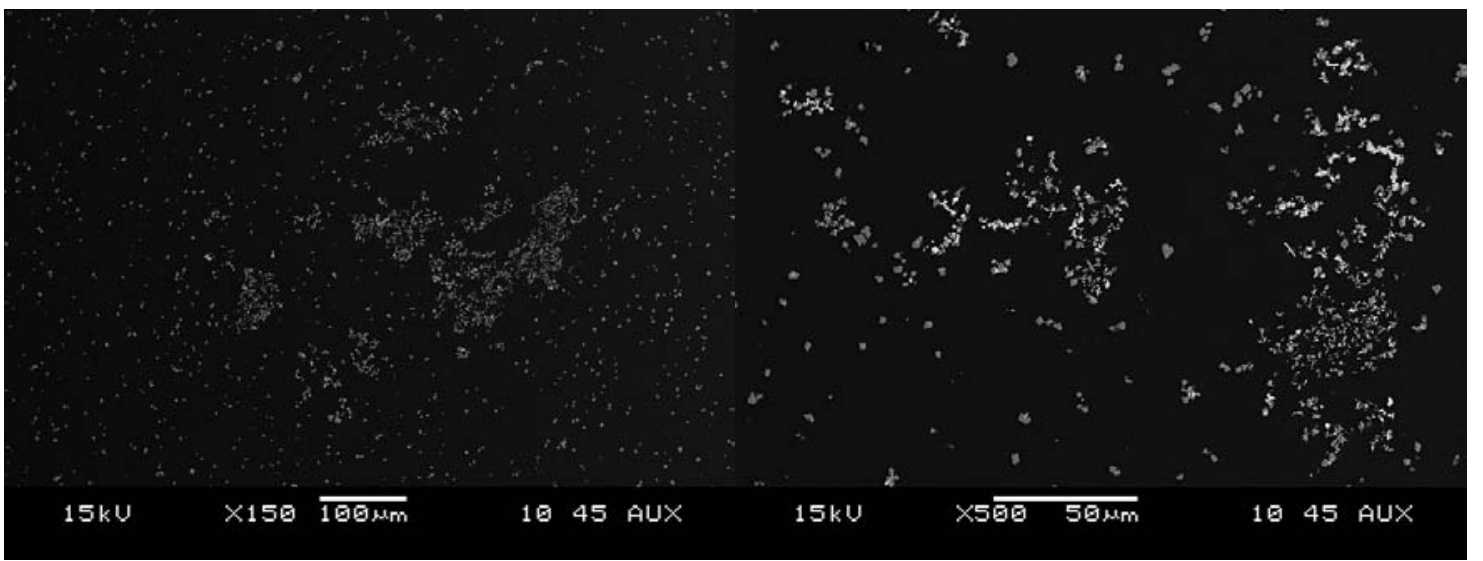

C

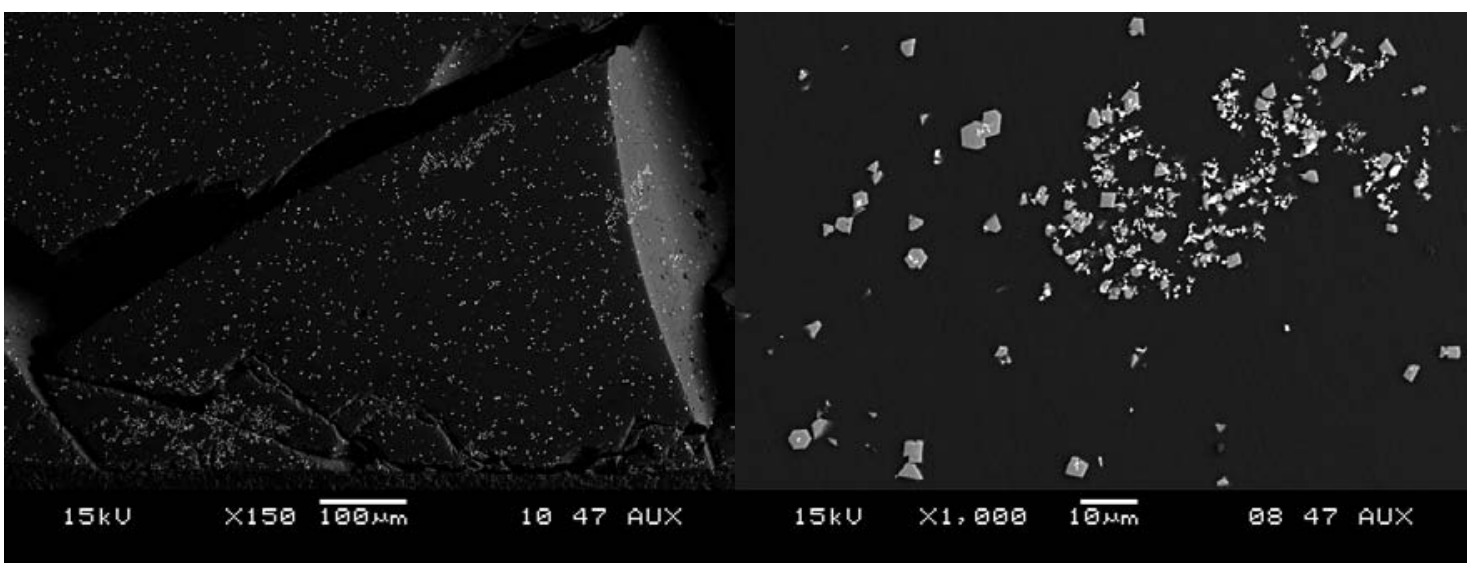

Figure 21. Agglomeration in the $\mathrm{Ni} 1.5 / \mathrm{RuO}_{2}$ Glass Heat-Treated at $850^{\circ} \mathrm{C}$ for A) 1 Day 21 Hours 15 Minutes, B) 3 Days 2 Hours 45 Minutes, and C) 4 Days 5 Minutes. Gray crystals are spinel, white specs are $\mathrm{RuO}_{2}$, dark gray is the glass. 
A

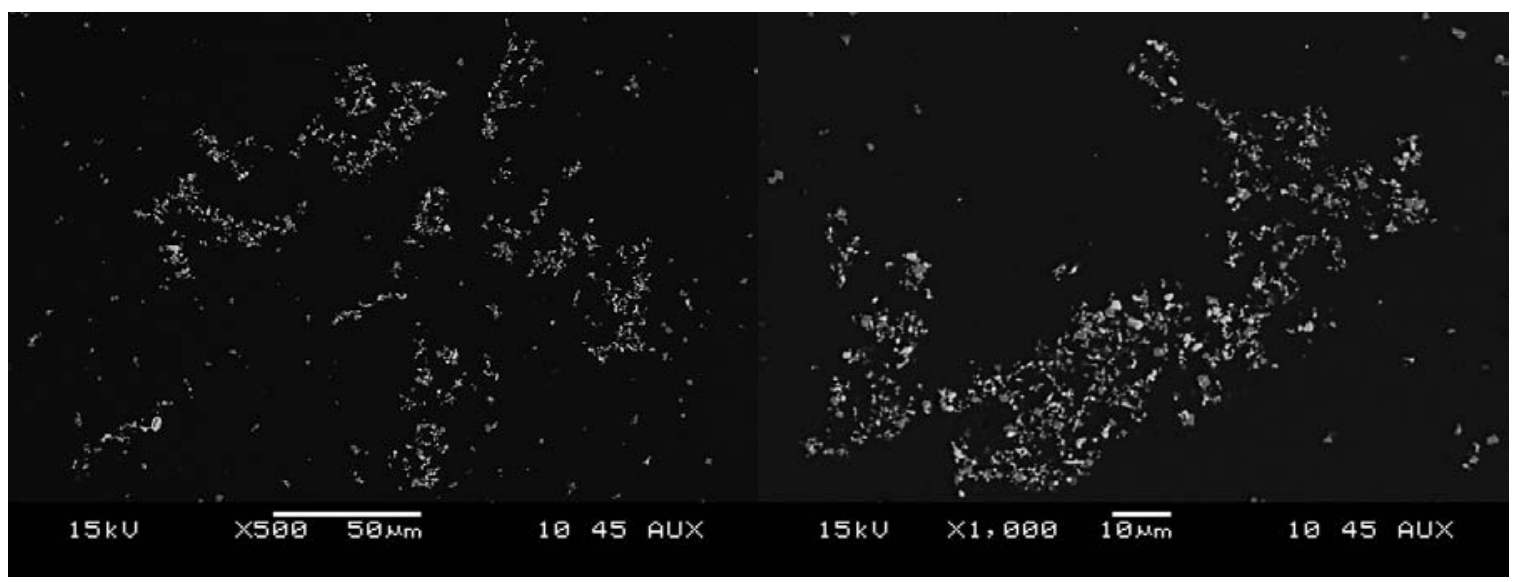

B

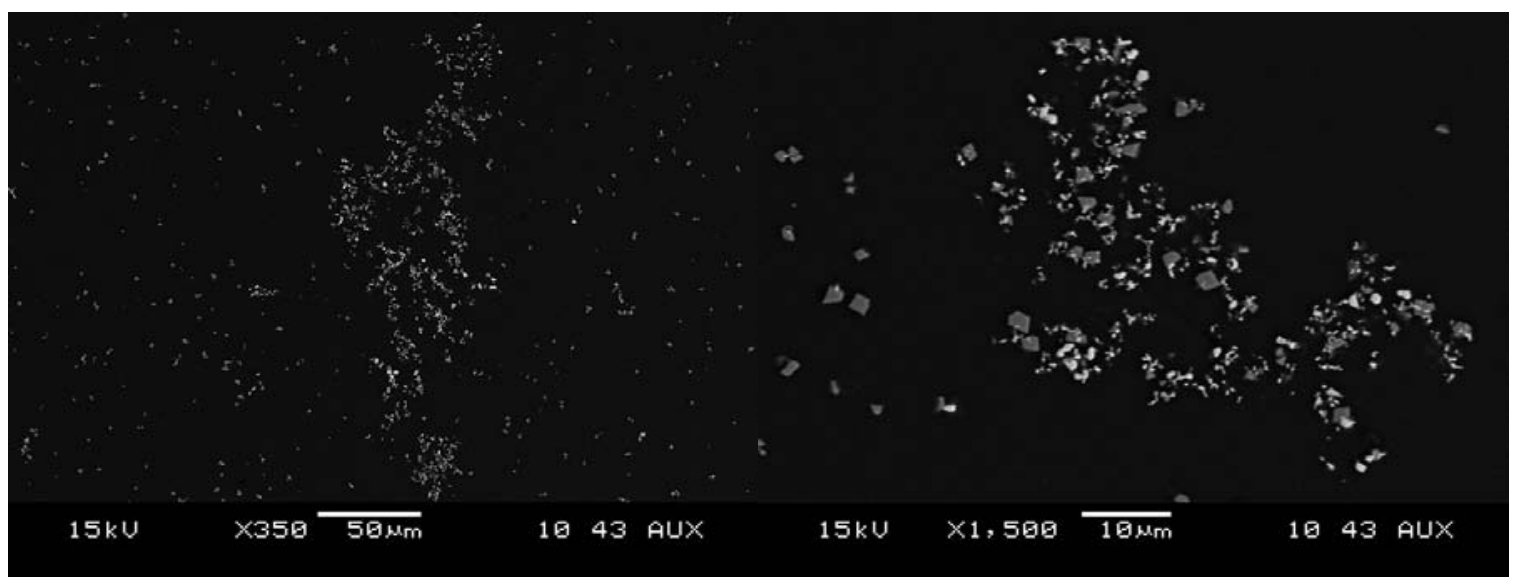

Figure 22. Agglomeration in the $\mathrm{BL} / \mathrm{RuO}_{2}$ Glass Heat-Treated at $850^{\circ} \mathrm{C}$ for $\left.\mathrm{A}\right) 2$ Days and B) 3 Days 21 Hours 25 Minutes. Gray crystals are spinel, white specs are $\mathrm{RuO}_{2}$, dark gray is the glass.

\subsection{Conclusions}

Adding 3 mass $\%$ of $\mathrm{Fe}_{2} \mathrm{O}_{3}$ to high-nickel glass resulted in the large-scale agglomeration, and therefore, fast accumulation rates. High concentration of spinel also formed in high-nickel glasses containing an extra $\mathrm{Al}_{2} \mathrm{O}_{3}$ and $\mathrm{Li}_{2} \mathrm{O}$ but these components promoted the growth of a network of needlelike spinel structures, preventing the formation of dense layers. Adding $\mathrm{RuO}_{2}$ to high-nickel glass decreased the crystal size to less than $10 \mu \mathrm{m}$, and therefore, prevented crystals from settling. Our settling model predicts well the accumulation of crystals in the glasses with no or small-scale agglomeration, in which spinel settles as individual crystals and/or as clusters of a few crystals. But, more experimental data is needed to make the model more robust to account for the effect of agglomeration and different crystal morphologies on accumulation rate and structure (dense vs. non-compacted) of the layer. Analysis of agglomerates suggested that X-ray tomography coupled with SEM and image analysis is an efficient tool to study agglomeration of particles in the glasses. 


\subsection{References}

10 CFR 830, Subpart A. 2010. “Nuclear Safety Management,” Subpart A, “Quality Assurance Requirements.” Code of Federal Regulations, U.S. Department of Energy.

Alton J, TJ Plaisted, and P Hrma. 2002a. "Dissolution and Growth of Spinel Crystals in a Borosilicate Glass.” Journal of Non-Crystalline Solids 311:24-35.

Alton J, TJ Plaisted, and P Hrma. 2002b. "Kinetics of Growth of Spinel Crystals in a Borosilicate Glass.” Chemical Engineering Science 57:2503-2509.

ASME NQA-1-2004. 2004. Quality Assurance Program for Nuclear Facilities Applications. American Society of Mechanical Engineers, New York.

DOE Order 414.1C. 2005. “Quality Assurance.” U.S. Department of Energy, Washington, D.C.

Eibling RE, RF Schumacher, and EK Hansen. 2003. Development of Simulants to Support Mixing Tests for High Level Waste and Low Activity Waste. SRT-RPP-2003-00098, REV. 0, Westinghouse Savannah River Company, Aiken, South Caroline.

Fox KM, DK Peeler, TB Edwards, DR Best, IA Reamer, RJ Workman, JC Marra, BJ Riley, JD Vienna, JV Crum, J Matyáš, AB Edmondson, JB Lang, NM Ibarra, A Fluegel, A Aloy, AV Trofimenko, and R Soshnikov. 2008. International Study of Aluminum Impacts on Crystallization in U.S. High Level Waste Glass. SRNS-STI-2008-00057, Savannah River National Laboratory, Aiken, South Carolina.

Hrma P, J Matyáš, and DS Kim. 2003. "Evaluation of Crystallinity Constraint for HLW Glass Processing.” Ceramic Transactions 143:133-140.

Izak P, P Hrma, BW Arey, and TJ Plaisted. 2001. "Effect of Feed Melting, Temperature History, and Minor Component Addition on Spinel Crystallization in High-Level Waste Glass.” Journal of NonCrystalline Solids 289:17-29.

Jiricka M, P Hrma, and JD Vienna. 2003. "The Effect of Composition on Spinel Crystals Equilibrium in Low-Silica High-Level Waste Glasses.” Journal of Non-Crystalline Solids 319:280-288.

Kalender WA. 2000. Computed Tomography Fundamentals of System Technology Image Quality Applications. MDC Werbeagentur GmbH, Munich, Germany.

Ketcham RA and WD Carlson. 2001. "Acquisition, Optimization and Interpretation of X-ray Computed Tomographic Imagery: Applications to Geosciences.” Computers \& Geosciences 27:381-400.

Kim DS and JD Vienna. 2002. "Influence of Glass Property Restrictions on Hanford Glass Volume.” Ceramic Transactions 132:105-115.

Kloužek J, J Alton, TJ Plaisted, and P Hrma. 2001. "Crucible Study of Spinel Settling in High-Level Waste Glass.” Ceramic Transactions 119:301-308. 
LaMont J and P Hrma. 1998. “A Crucible Study of Spinel Settling in a High-Level Waste Glass.” Ceramic Transactions 87:343-348.

Matlack KS, WK Kot, W Gong, W Lutze, IL Pegg, and I Joseph. 2009. Effects of High Spinel and Chromium Oxide Crystal Contents on Simulated HLW Vitrification in DM100 Melter Tests.

VSL-09R1520-1, U.S. Department of Energy Office of River Protection, Richland, Washington.

Matyáš J, J Kloužek, L Němec, and M Trochta. 2001. “Spinel Settling in HLW Melters.” ICEM’01 The 8th International Conference on Environmental Management, Bruges, Belgium.

Matyáš J, JD Vienna, MJ Schaible, CP Rodriquez, and JV Crum. 2010a. Development of CrystalTolerant High-Level Waste Glasses. PNNL-20072, Pacific Northwest National Laboratory, Richland, Washington.

Matyáš J, JD Vienna, A Kimura, M Schaible, and RM Tate. 2010b. “Development of Crystal-Tolerant Waste Glasses.” Ceramic Transactions 222:41-51.

Matyáš J, JD Vienna, and MJ Schaible. 2011. “Determination of Stokes Shape Factor for Single Particles and Agglomerates.” Ceramic Transactions 227:195-203.

McGrail BP, EM Pierce, HT Schaef, EA Rodriguez, JL Steele, AT Owen, and DM Wellman. 2003. Laboratory Testing of Bulk Vitrified and Steam Reformed Low-Activity Waste Forms to Support A Preliminary Risk Assessment for an Integrated Disposal Facility. PNNL-14414, Pacific Northwest National Laboratory, Richland, Washington.

Mika M, M Liska, and P Hrma. 2002. “The Effect of Spinel Sludge Aging on its Viscosity.” CeramicsSilikaty 46(4):148-151.

Mika M, P Hrma, and MJ Schweiger. 2000. "Rheology of Spinel Sludge in Molten Glass.” CeramicsSilikaty 44(3):86-90.

Stachnik MW, P Hrma, and H Li. 2000. "Effects of High-level Waste Glass Composition on Spinel Precipitation.” Ceramic Transactions 107:123-130.

Wellman DM, JP Icenhower, and AT Owen. 2005. Comparative Analysis of Soluble Phosphate Amendments for the Remediation of Heavy Metal Contaminants: Effect on Sediment Hydraulic Conductivity. PNNL-SA-44734, Pacific Northwest National Laboratory, Richland, Washington.

Wilson BK, P Hrma, J Alton, TJ Plaisted, and JD Vienna. 2002. "The Effect of Composition on Spinel Equilibrium and Crystal Size in High-Level Waste Glass.” Journal of Material Science 37:5327-5311. 



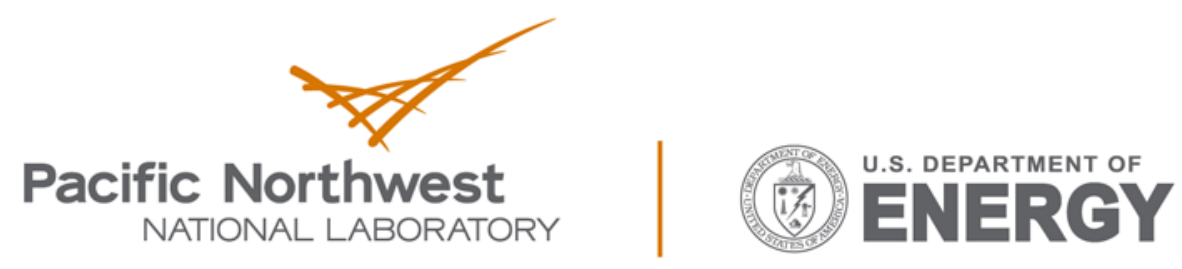

Proudly Operated by Battelle Since 1965

902 Battelle Boulevard

P.O. Box 999

Richland, WA 99352

1-888-375-PNNL (7665)

www.pnnl.gov 